\title{
Spotlight on eudaimonia and depression. A systematic review of the literature over the past 5 years
}

\section{Chiara Ruini \\ Giulia Cesetti}

Department of Psychology, University of Bologna, Bologna, Italy
Correspondence: Chiara Ruini Department of Psychology, University of Bologna, Viale Berti pichat 5, Bologna 40I27, Italy

Tel +3905I 2091817

Fax +3905 I24 3086

Email chiara.ruini@unibo.it
This article was published in the following Dove Press journal: Psychology Research and Behavior Management

Background and aim: Recent investigations pointed out to the important role of wellbeing in influencing physical and mental health, with robust findings for the dimension of depression. The aim of this systematic review is to provide an updated summary of articles focused on eudaimonia and depression, including psychosocial interventions that addressed both issues.

Method: The literature search was performed by entering the keywords: "eudaimonia" OR "eudaimonic well-being (EWB)" and "depression" and by limiting to "journal article" and to the English language. To be included in this, review articles had to present at least one EWB measure and one depression measure, and had to investigate young and adult populations, including populations with mental health disorders. Articles were excluded if they were published before 2014.

Results: Thirty-four articles were included, with a total of 81,987 participants. About the majority of participants were recruited in two twin studies, followed by college students, and by adults belonging to the general and clinical populations. Sixteen different instruments assessed eudaimonia, being Ryff's psychological well-being scale the most frequently used. The most used instrument for assessing depression was the Depression Anxiety Stress Scale, followed by Center for Epidemiological Studies Depression Scale. The studies confirmed the robust, inverse correlation between eudaimonia and depression, which was only partially explained by genetic common factors and which was mediated by other factors, as selfcompassion, personality traits, and defense mechanisms. Various interventions were found to be effective both in promoting eudaimonia and in addressing depression, ranging from cognitive-behavioral therapy, acceptance and commitment therapy, mindfulness, to positive psychotherapy.

Conclusion: Clinicians, counselors, and practitioners can select different strategies to promote EWB and to address depression. The findings also suggest the need for a larger consensus on the definition of eudaimonia and on the specific measure(s) to evaluate it in different populations and in different life stages.

Keywords: eudaimonia, depression, well-being, recovery, adulthood, mental health

\section{Introduction}

The recent, growing research in positive psychology has focused on the domains of health and well-being and it distinguished between the hedonic approach and the eudaimonic one. ${ }^{1-4}$ The concept of hedonic or subjective well-being refers to the pursuit of pleasure and the presence of a sense of life satisfaction. ${ }^{5,6}$ The concept of eudaimonic well-being (EWB), on the other hand, refers to optimal human 
functioning and the endeavor to achieve meaningful goals in life. ${ }^{2,4}$ It is referred to in the literature also as psychological well-being (PWB), ${ }^{1,2}$ or personal expressiveness, ${ }^{7}$ self-realization, ${ }^{8}$ meaning in life, ${ }^{9}$ or engaged/full life, ${ }^{10,11}$ among others. Huta and Waterman ${ }^{4}$ distilled eleven models with comprehensive measures of EWB, which included those referring to orientations, goals, and motivations and those involving emotional, cognitive, and social wellbeing components. According to Huta and Waterman, the model of EWB that received more consensus is the one proposed by Ryff, ${ }^{2}$ which encompasses six interrelated dimensions: autonomy, purpose in life, positive relations, self-acceptance, personal growth, and environmental mastery. On the same vein, Waterman ${ }^{7}$ and Ryan, and Huta and Deci $^{8}$ described eudaimonia as the capacity to develop oneself over time, by cultivating specific personal characteristics such as autonomy and self-determination, positive interpersonal functioning, and a sense of mastery in managing life circumstances. On the other hand, Steger et $\mathrm{al}^{9}$ emphasized the dimension of meaning, which gives a sense of purpose to daily activities. Another different definition of eudaimonia derives from the model of "full life", ${ }^{11}$ where the dimension of meaning is linked to the one of life engagement, as opposed to the "empty life", where meaning and engagement are lacking.

However, a comprehensive and unique approach to eudaimonia is not available in the current positive psychology literature. Furthermore, the term "eudaimonia" has become scientifically recognized and used in psychological literature only very recently. ${ }^{4}$ This term has been generally applied to investigate the global "optimal" or "positive" functioning of individuals. ${ }^{2,4}$ Under the EWBumbrella, thus, investigators measured and addressed either Ryff's model, ${ }^{1,2}$ or Waterman's ${ }^{7}$ or Ryan et al's one ${ }^{8}$ often without specific selection criteria.

Despite this variety of definitions and approaches, there is an emerging concordance in recent investigations, which points out to the important role of EWB in influencing physical and mental health. A recent review by Ryff ${ }^{2}$ documented the significant inverse association between eudaimonia and mortality, chronic illness, and adverse health outcomes. Further investigations documented the same pattern of relationships, particularly for the dimension of purpose in life. ${ }^{12,13}$ More recently, investigations about the genetic underpinning of $\mathrm{EWB}^{14,15}$ shed more light on the biological mechanisms involved in this protective role for health. Higher levels of EWB (but not hedonic) were found to be associated with a diminished activation of the conserved transcriptional response to adversity (CTRA) mechanism. CTRA is characterized by increased expression of genes involved in inflammation and decreased expression of genes involved in antiviral and antibody responses. Thus, individuals with high levels of eudaimonia may present a healthier profile when confronted with stress, particularly when it comes from social situations or interactions. ${ }^{16}$ This finding might also explain the strong, inverse correlations between eudaimonia and mental health.

The model of EWB proposed by Ryff, ${ }^{1,2}$ in fact, was found to be negatively associated with depression in adults ${ }^{17-21}$ older adults $^{22-24}$ and adolescent populations. ${ }^{25-27}$ A pivotal longitudinal investigation ${ }^{28}$ found that individuals with initial low EWB were over twice as likely to be depressed 10 years later compared to those with higher levels, after controlling for personality, negative functioning, prior depression, demographic, economic, and physical heath variables. In clinical settings, a specific sequential psychotherapy, which combined traditional cognitive-behavioral strategies with the promotion of eudaimonia (well-being therapy), was found to reduce the risk of relapse in recurrent depression up to 6 years. ${ }^{18}$ Another study with older adults living in residential care demonstrated that one specific dimension of EWB - ie, environmental mastery - could predict up to $50 \%$ of the variance in participants' depression. ${ }^{29}$

Thus, a growing number of investigations suggested that EWB protects mental health, but few studies involved clinical samples. ${ }^{30}$ The few exceptions suggested that factors relating to positive psychological functioning might be involved in the psychopathological mechanisms contributing to depression, ${ }^{31}$ such as the difficulties in experiencing and maintaining positive emotions ${ }^{32}$ or specific self-judgment bias. ${ }^{33}$

A recent systematic review ${ }^{30}$ also found that EWB was impaired in adults with depression and other psychiatric disorders, and that the specific dimension of autonomy appeared to influence patients' motivation to seek and to adhere to treatment. The same review ${ }^{30}$ documented that the impairments in EWB may be improved by specific interventions such as acceptance and commitment therapy, mindfulness, positive psychotherapy, or other positive interventions. Other recent meta-analyses ${ }^{34,35}$ confirmed the efficacy of positive interventions - those explicitly aimed at promoting well-being - in improving well-being dimensions as well as in improving depression, or other symptoms of psychological distress. On the same vein, traditional interventions such as cognitive-behavioral therapy (CBT) 
demonstrated their beneficial effects on both symptoms of depression and on indicators of positive functioning. ${ }^{18,36,37}$ However, to the best of our knowledge, previous reviews and meta-analyses ${ }^{30,34,35}$ addressed well-being and distress at a more general level, without scoping into eudaimonic dimensions and into their relationships with depression. Eudaimonia and depression appear to be connected by intertwined mechanisms. These mechanisms rely on the balance between positive and negative affects. ${ }^{38,39}$ If treatment of symptoms induces improvement of EWB, it is conceivable that also changes in well-being may affect the balance of positive and negative affects and the depressive state of individuals. ${ }^{40}$

Shedding more light on these mechanisms appears to be fundamental, both in general and clinical populations. Considering the availability of previous literature and review articles, ${ }^{2,34,35}$ and the rapidly growing research in this filed, an updated review on the relationship between eudaimonia and depression is the primary aim of the present article, which will be focused over the last 5 years. We selected this time frame since the term eudaimonia was systematically used in psychological literature only recently, particularly after Ryff's and Huta and Waterman's reviews. ${ }^{2,4}$ In the present review, we aim to provide an updated summary of articles focused on eudaimonia and depression, including psychosocial interventions that addressed both issues.

\section{Method}

\section{Design}

A systematic review was performed in order to extract recently published scientific papers that dealt with measures of EWB and measures of depression in adult and emerging adult populations. We focused on the last 5 years (from 2014 on) in order to provide an update of the literature on eudaimonia and depression. The present review followed the guidelines for Preferred Reporting Items for Systematic reviews and Meta-Analyses. ${ }^{41}$

\section{Search method}

A systematic literature search was conducted on the following electronic databases: EBSCO host (PsychARTICLES, PsychINFO), PubMed, and Scopus. The literature search was performed by entering the keywords: "eudaimonia" OR "eudaimonic well-being" AND "depression" and by limiting to "journal article" and to the English language. Books, book chapters, dissertation or unpublished manuscript and review articles were excluded. No other search method was applied. Search strings were adapted according to the database, but spelling options were not permitted, in order to limit the results on the focus of the present review. The full search was conducted including articles up to January 2019. Additionally, reference lists of previous reviews or metaanalyses were screened in order to include potentially eligible studies.

\section{Selection criteria}

To be selected for this review, studies were required to 1) be full-text articles published in English, 2) include at least one EWB measure AND one depression measure, 3) investigate adult populations, including populations with mental health disorders. Articles were excluded if they were 4) published before 2014, 5) study protocols, 6) reviews, 7) validation studies, 8) qualitative investigations, and 9) if they included older adults or aging populations ( $>65$ years old). This latter criterion was selected since depression in later life has specific clinical features, which include cognitive impairments, somatic complaints, specific treatments options, and clinical outcomes. Thus, the clinical characteristics of depression in this life stage are not comparable to those of other age populations, and articles were excluded if they entirely focused on older adults or aging populations, or community dwellers.

\section{Search outcome}

The first screening identified 365 articles. The majority of them were extracted from EBSCO host and Scopus databases. Only few articles were extracted from PubMed. After removing duplicates, 330 publications were identified and individually assessed based on the study's title and the information provided in the abstract (see review flowchart as depicted in Figure 1). Of these works, 224 papers were excluded according to the inclusion and exclusion criteria described above, while the full texts of 106 articles were examined before the decision was made to include them or not. Of these 106 articles, 50 papers did not assess EWB in combination with depressive measures and they were excluded.Further ten papers were excluded as they were published before 2014. Fourteen more papers were excluded, as they included only older adults or aging populations. Two additional articles were added out of manual screening of reference list. A total of 34 papers met all the inclusion criteria, and were included in the present review. 


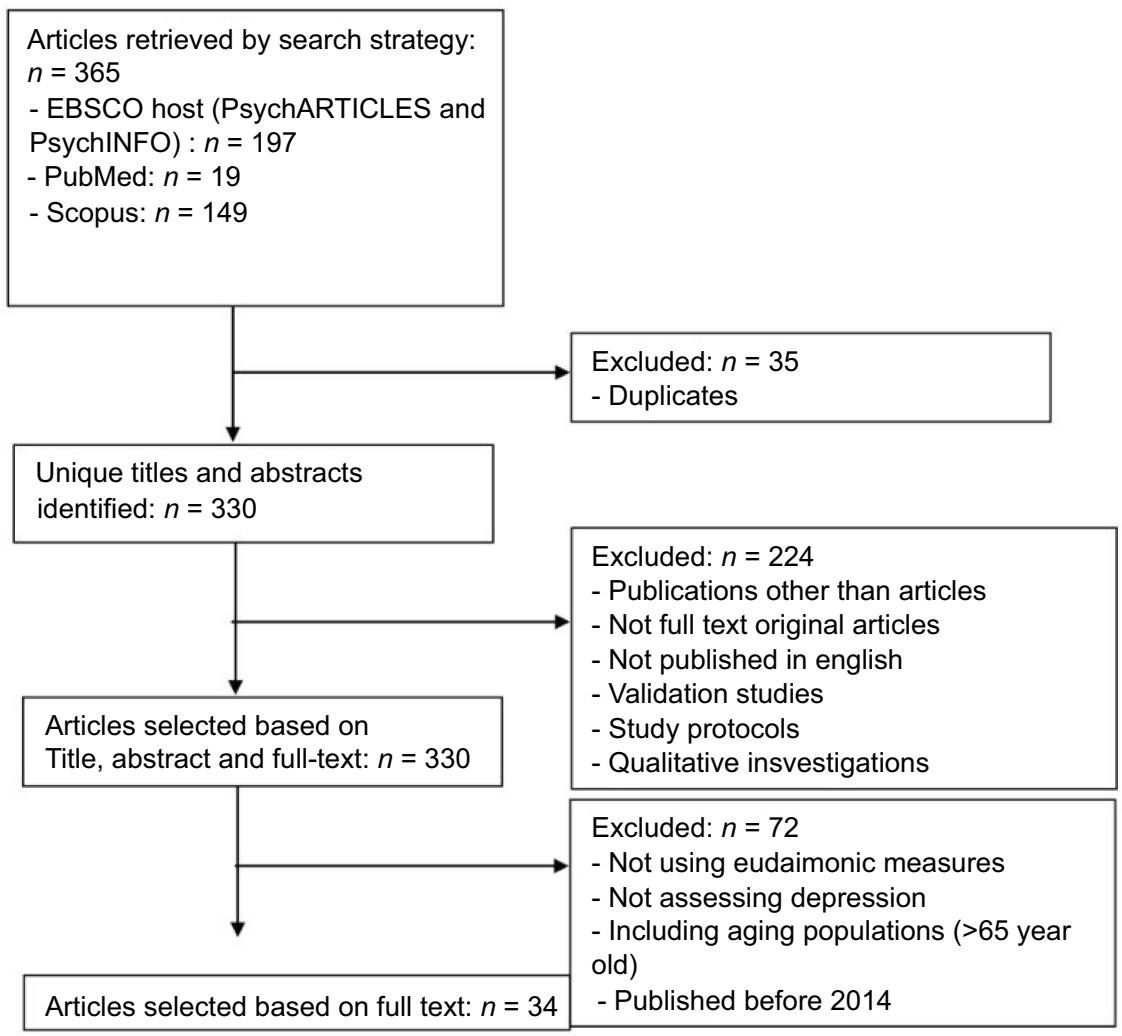

Figure I Review flowchart.

\section{Data collection}

The titles and abstracts for the articles assessed for potential inclusion were identified and independently inspected by one reviewer, who excluded duplicates and articles that clearly did not meet inclusion criteria. All potentially relevant articles were then fully assessed by another reviewer who decided upon inclusion. Uncertainty was resolved by coming to consensus. Data were extracted using a pre-designed template (see Table 1) with the following specified headings: measure of EWB and measure of depression used, country where the study was performed, population investigated, numbers of participants, study design, main objectives, and main results with effect sizes (when available).

\section{Results}

Thirty-four articles were included, with a total of 81,987 participants (including adolescents/ young adults and middle-aged individuals). Sixteen articles were cross-sectional (eight with a descriptive design, other eight with a comparative one). Other eight articles had a longitudinal design, six articles were randomized controlled studies, and other two studies included only twins and assessed genetic variables associated with EWB and depression. (see Table 2)

\section{Instruments for assessing eudaimonia}

Table 3 indicates the quantitative measures used for evaluating eudaimonia. The most used one was Ryff's PWB scale, ${ }^{1}$ which was applied in 13 investigations ${ }^{42-54}$ of 34 . Ryff's PWB was used in its longer version (84 items) or in its shorter ones (42 or 18 items). Some investigations ${ }^{42}$ applied just one dimension of the six included in the full model.

The second most used quantitative measure of eudaimonia was the Mental Health Continuum (MHC) ${ }^{55}$ which was used in six investigations. ${ }^{56-61} \mathrm{MHC}$ was computed as a quantitative variable (the higher the score, the higher the well-being), or as a categorical variable for evaluating the conditions of flourishing, languishing, or moderate mental health. ${ }^{55}$ Flourishing was also assessed with the Flourishing Scale ${ }^{62}$ in two investigations. ${ }^{51,63}$

Eudaimonia was also measured with the Meaning in Life Questionnaire ${ }^{9}$ in two articles, ${ }^{48,64}$ with the Pemberton Happiness Index ${ }^{65}$ in two articles, ${ }^{47,66}$ with the Eudaimonic and Hedonic Happiness Investigation ${ }^{67}$ 


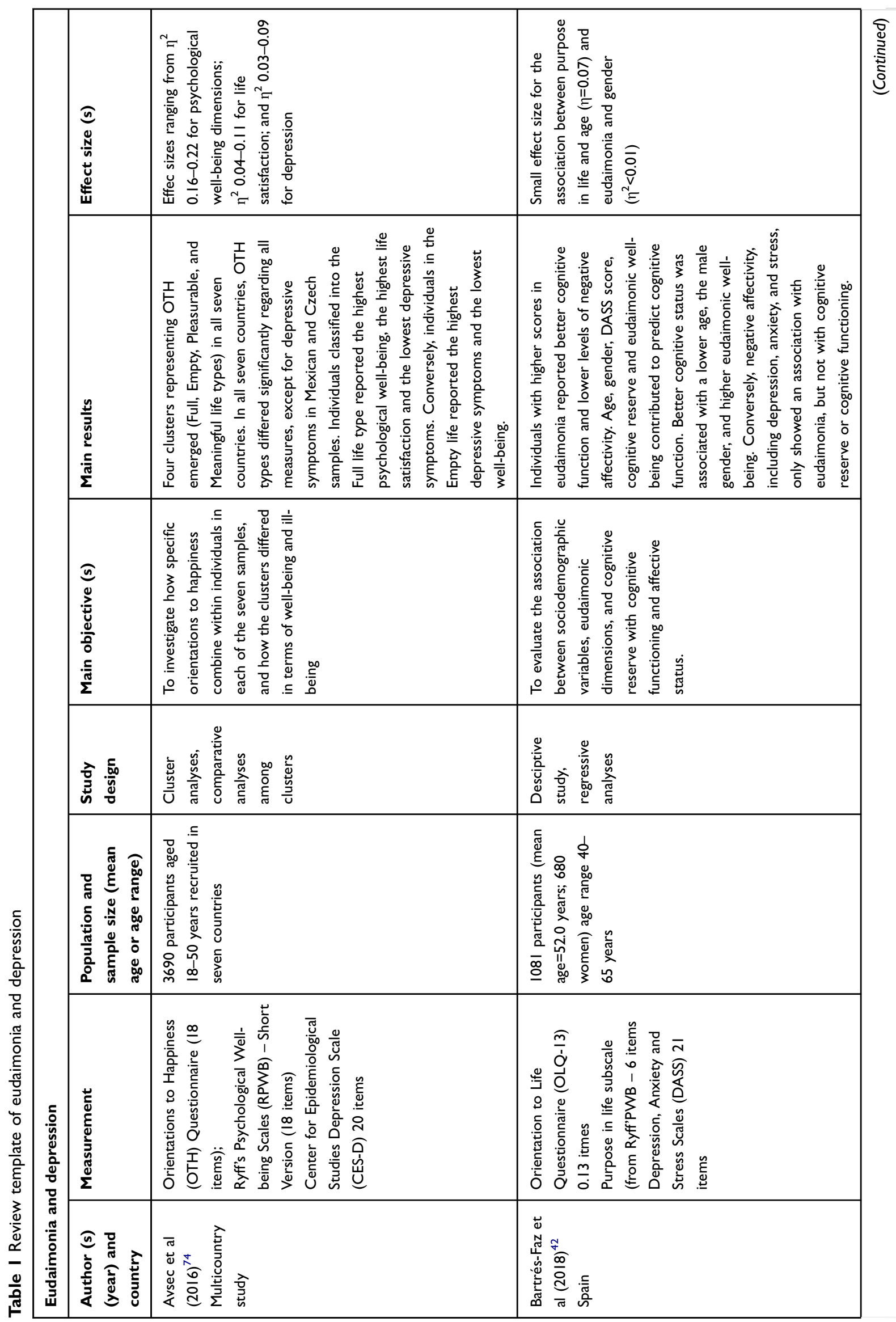




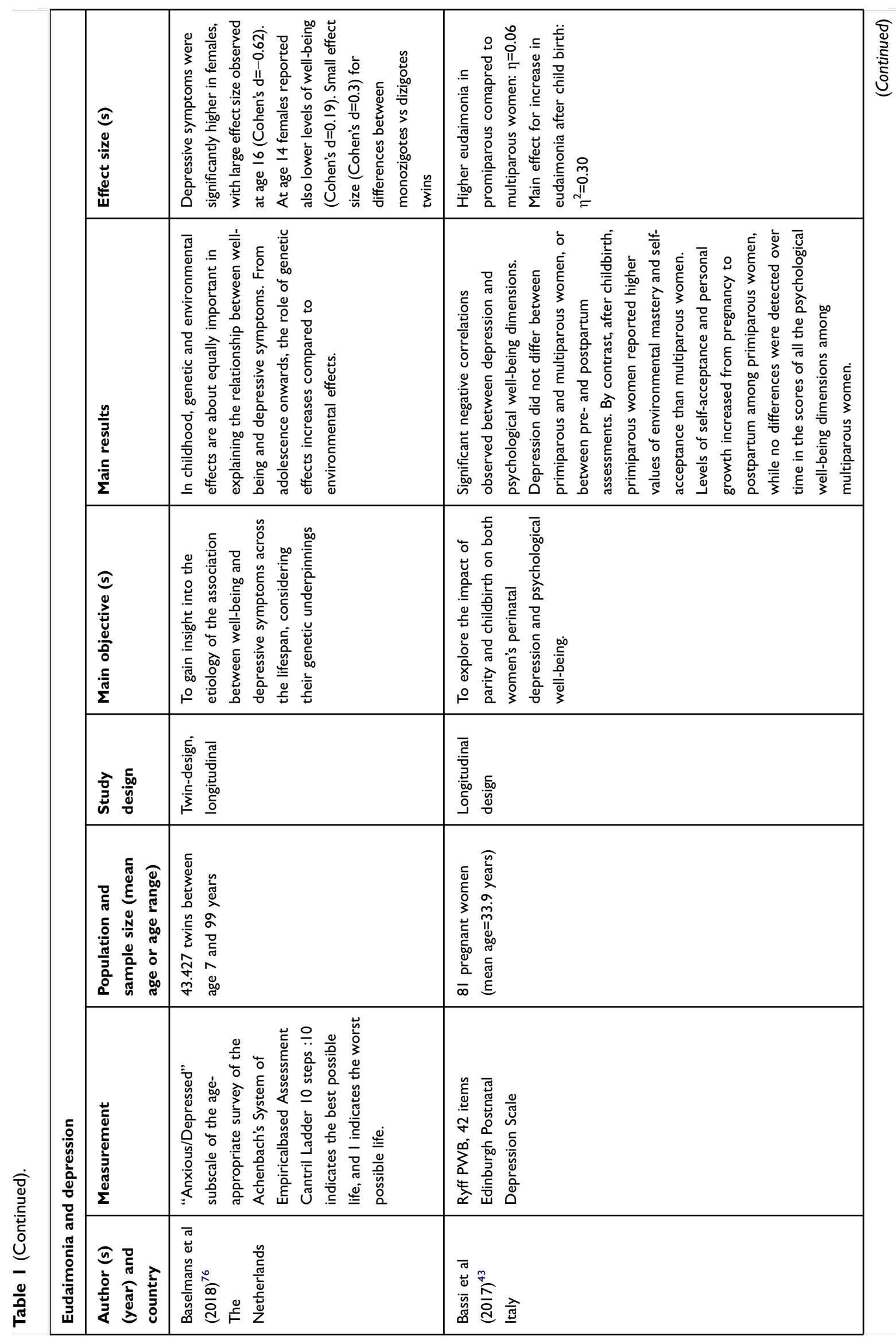




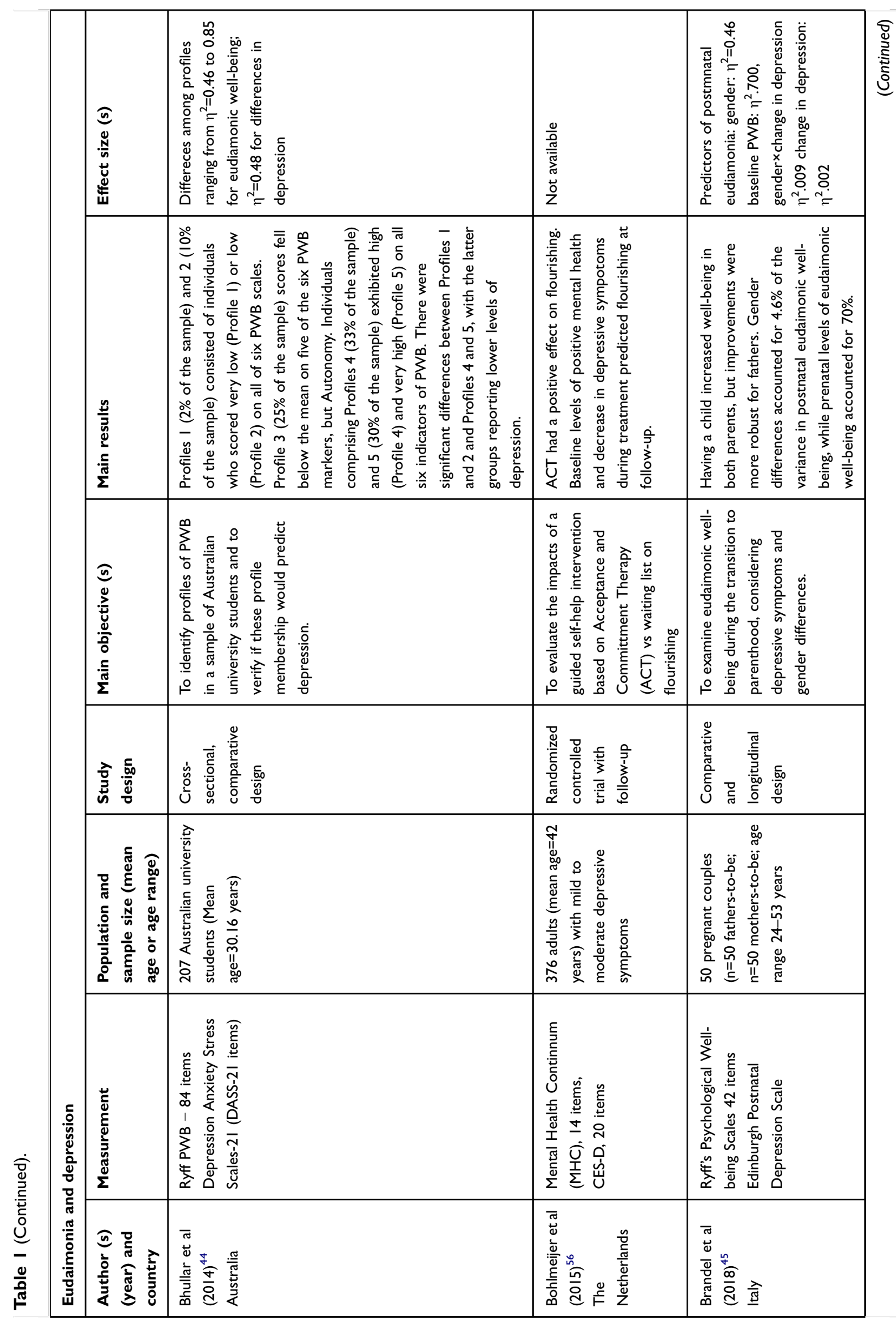




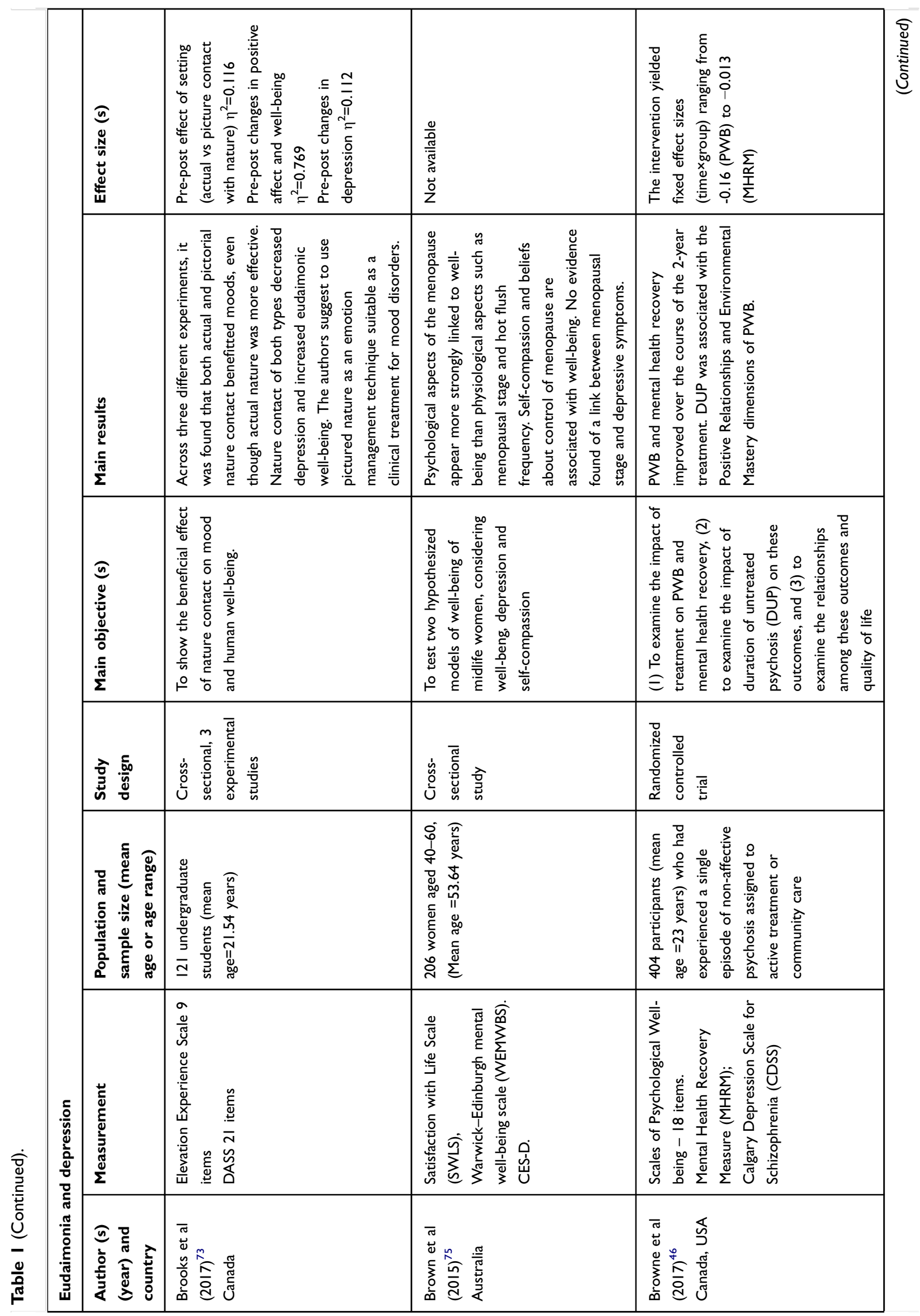




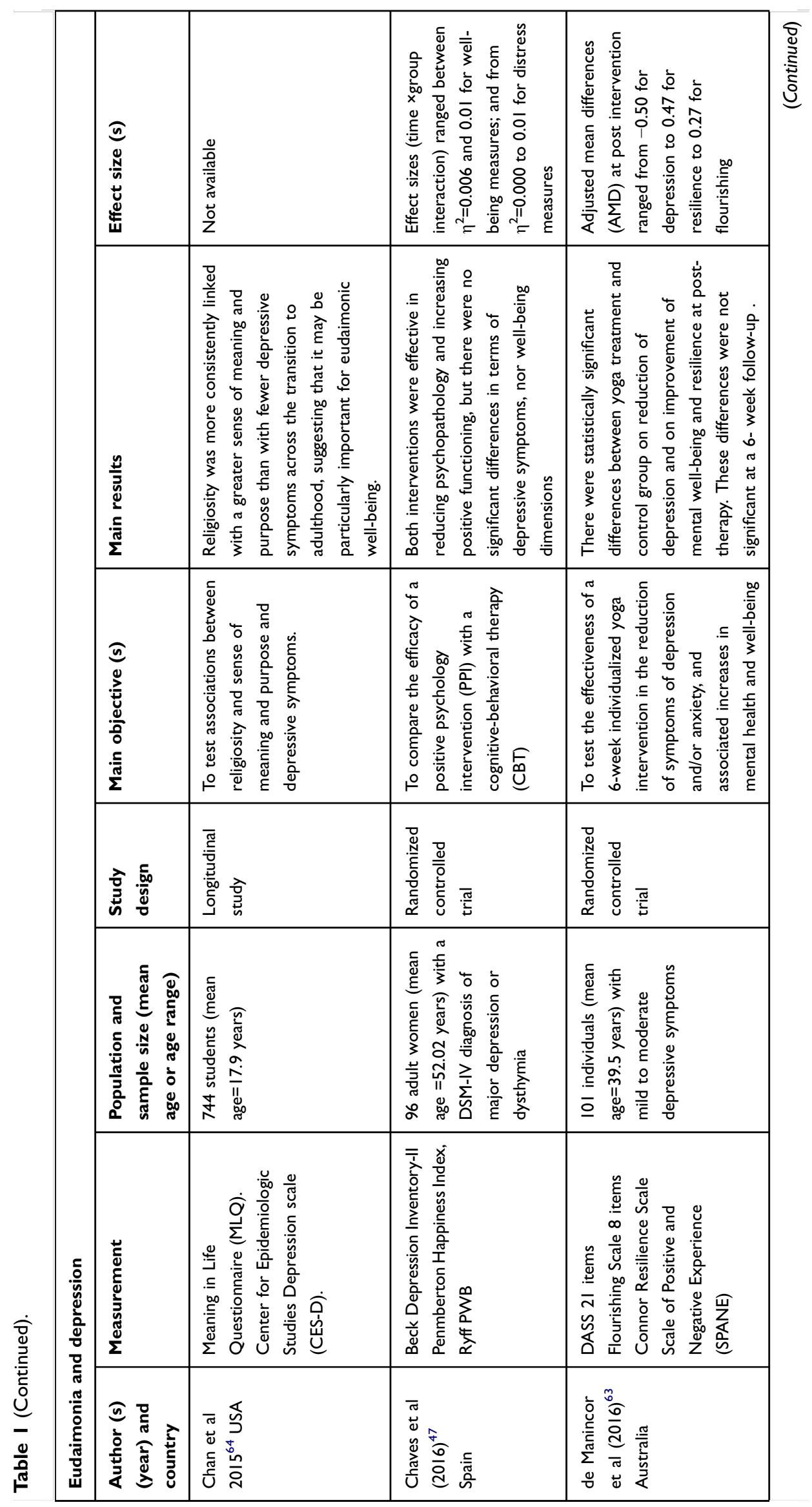




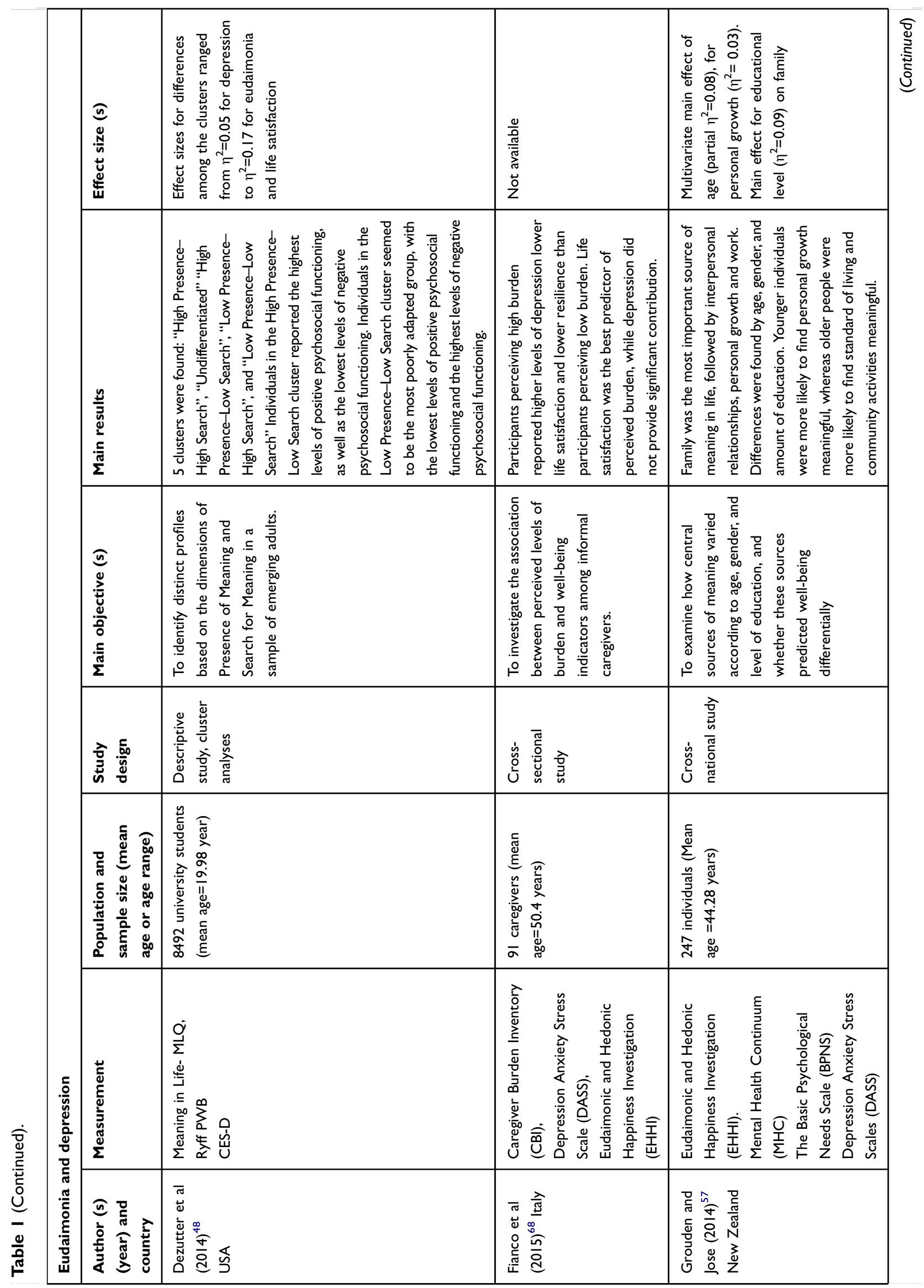




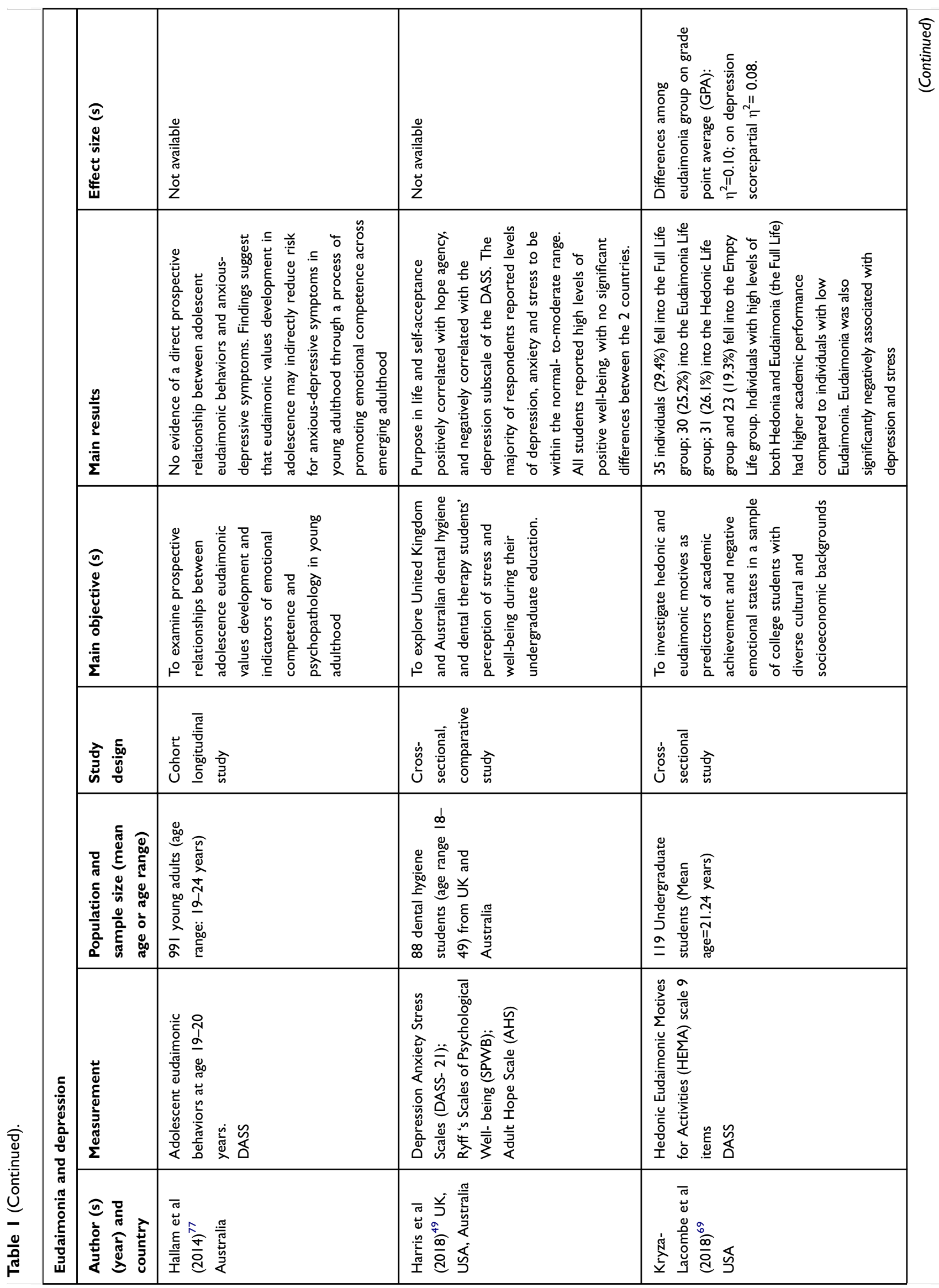




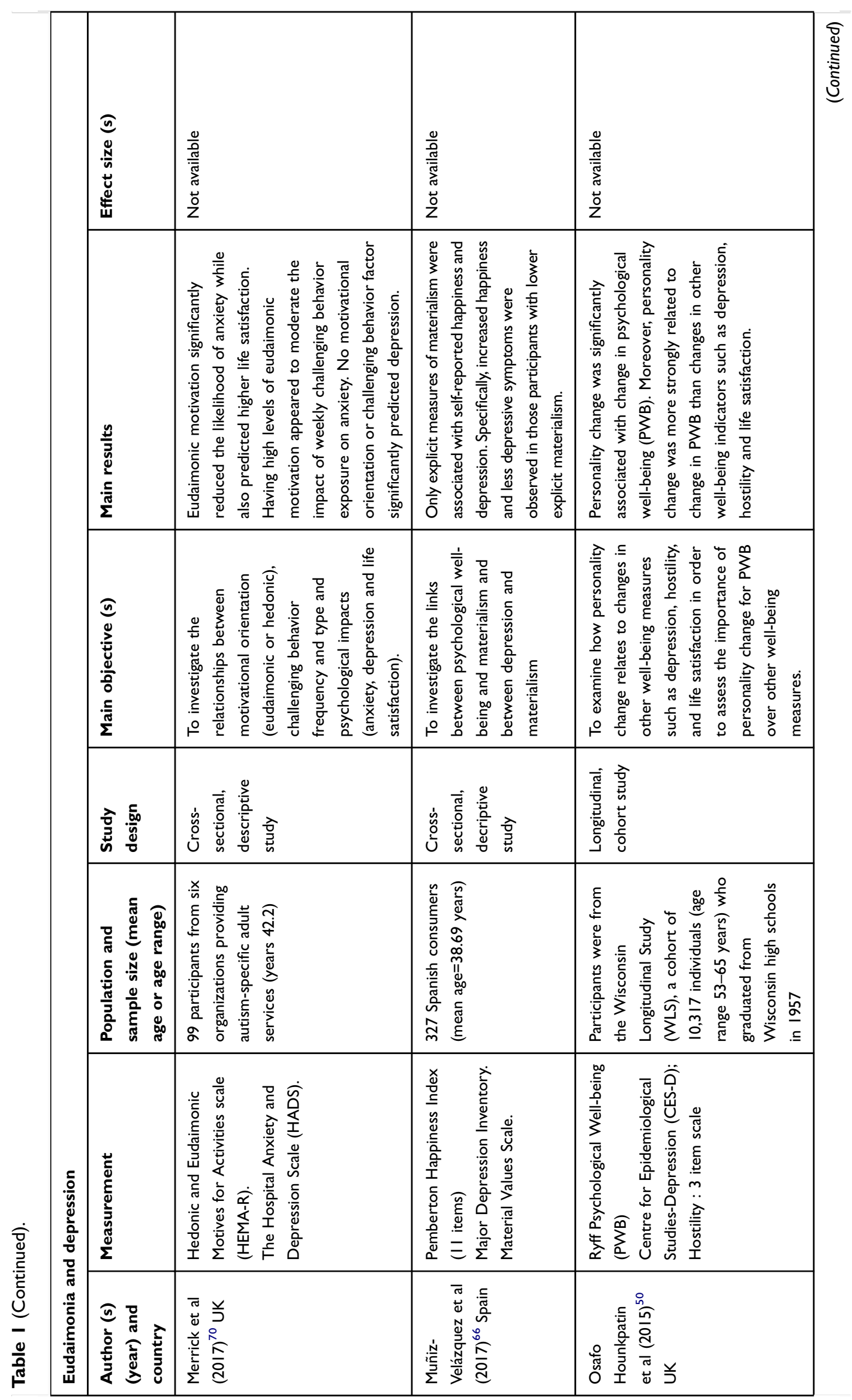




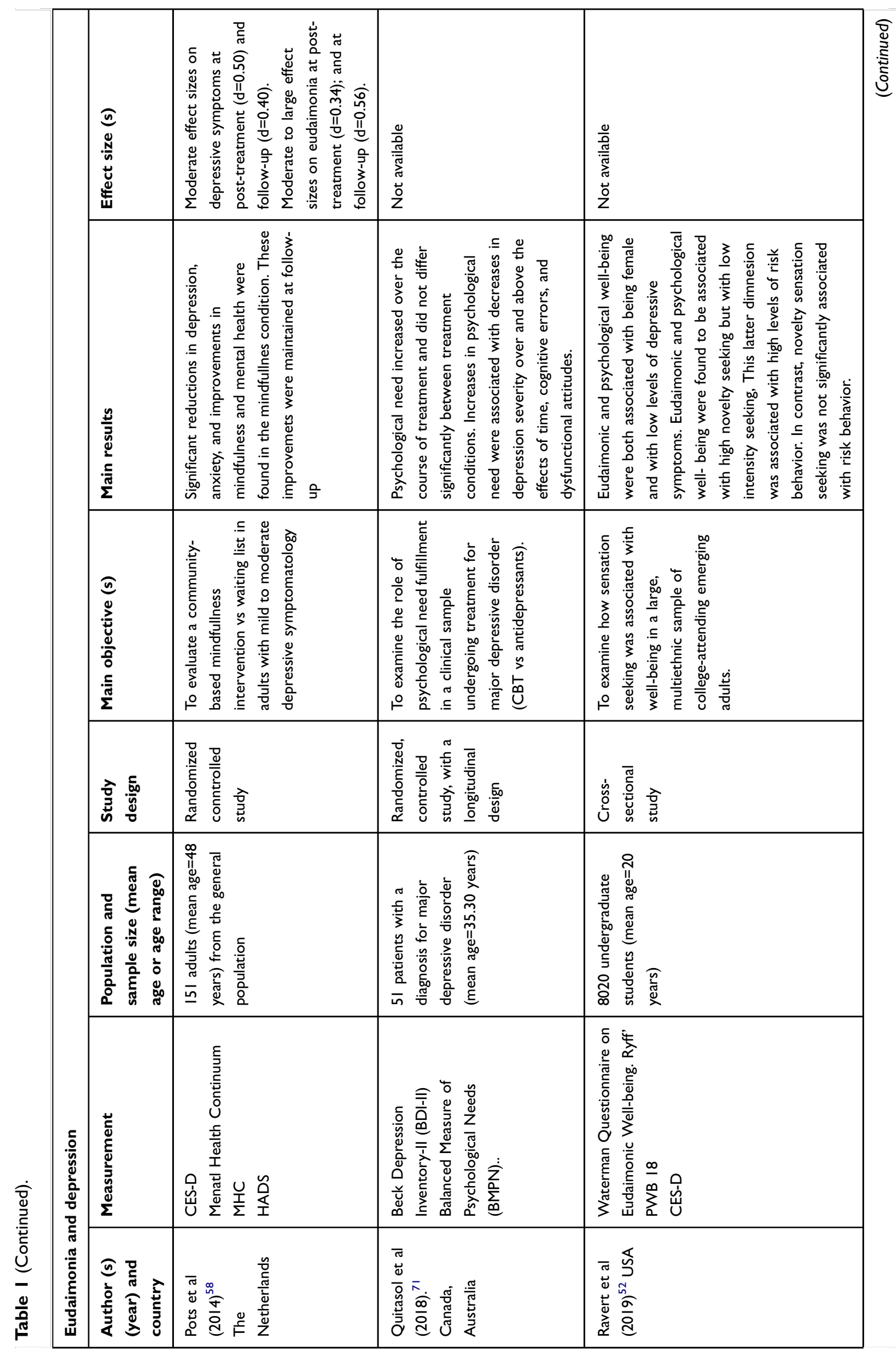




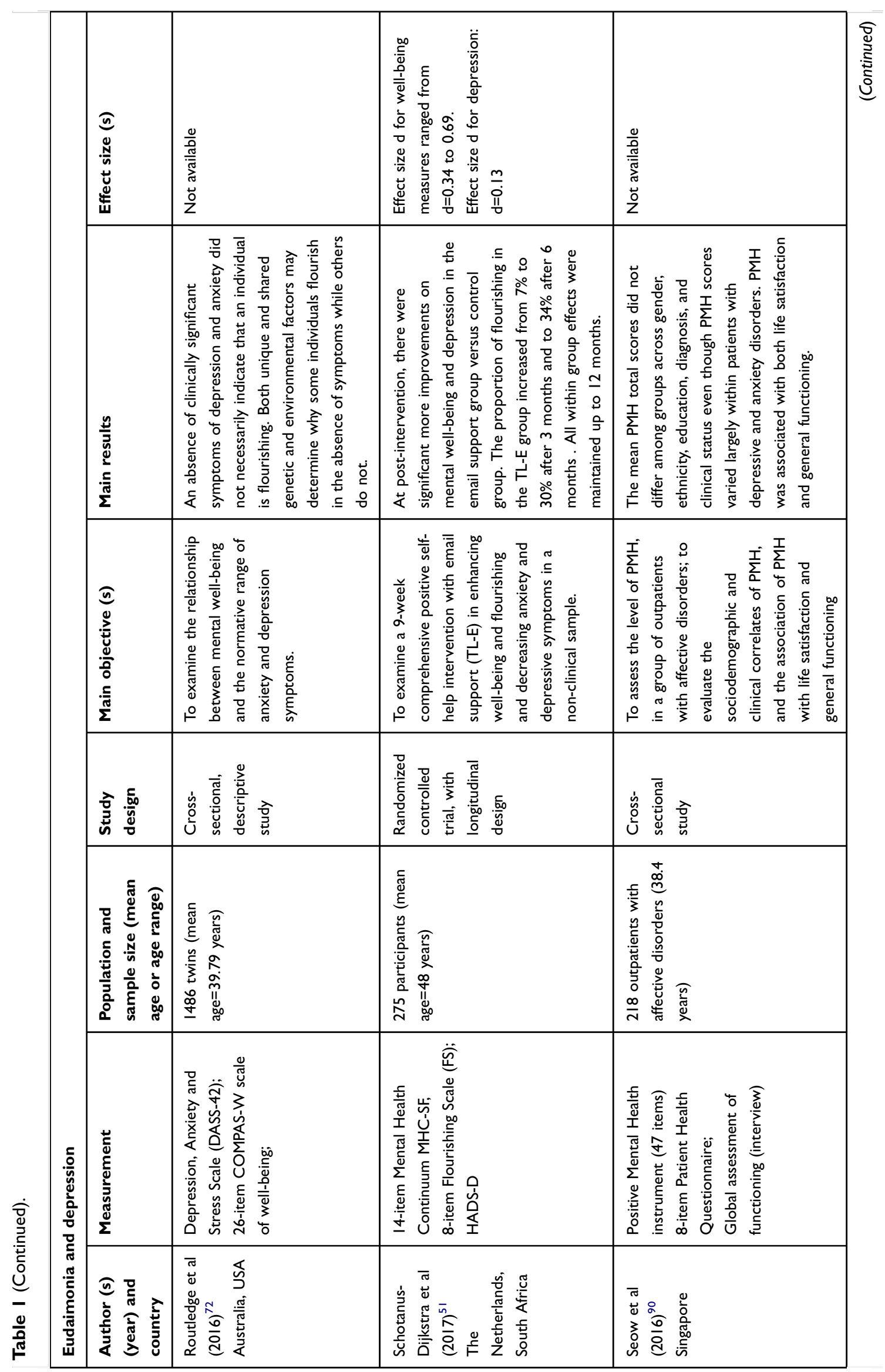




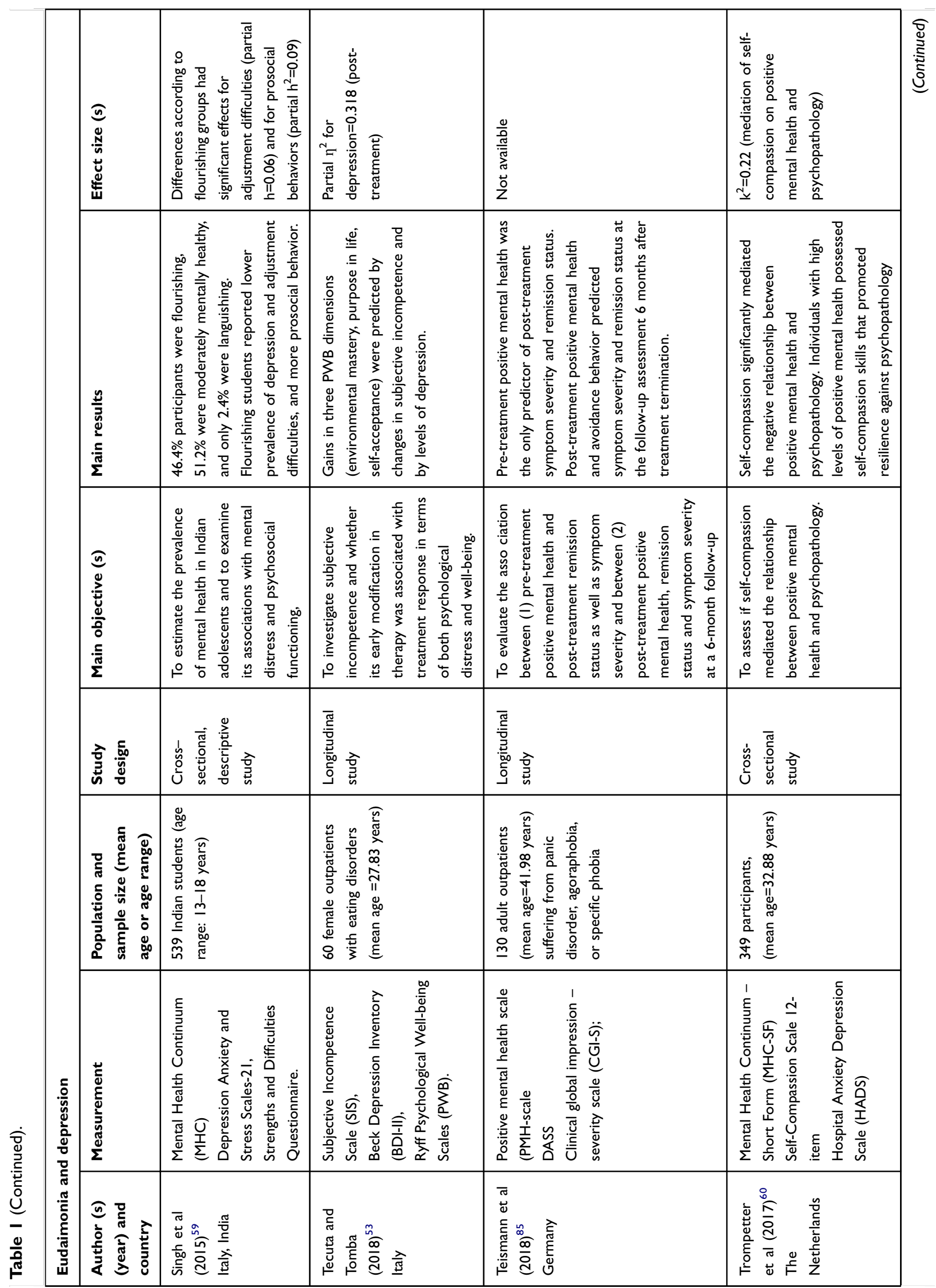




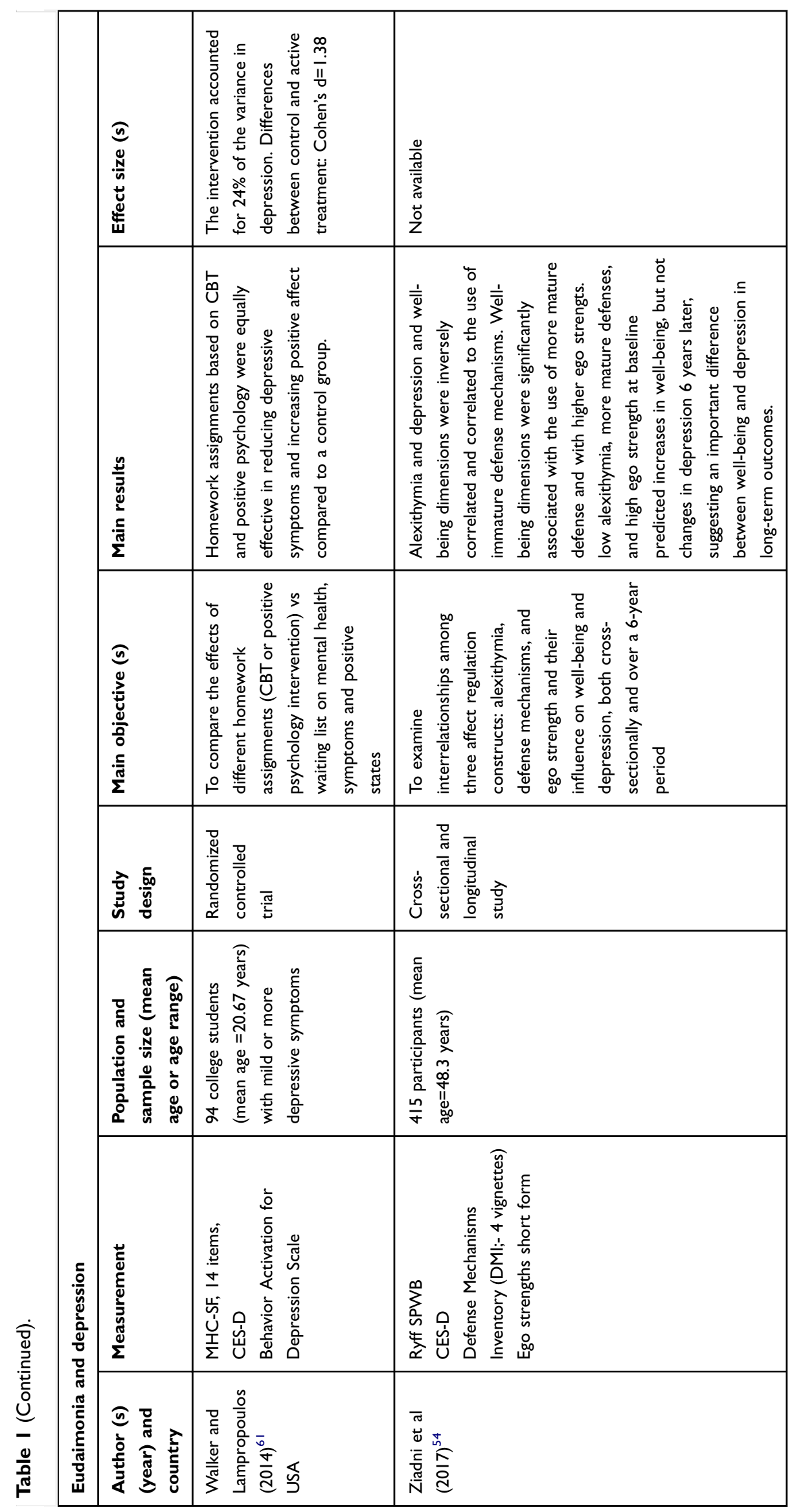


Table 2 Type of studies included in the review

\begin{tabular}{|l|l|}
\hline Type of study & Number of articles \\
\hline Cross-sectional (comparative design) & $8^{44,48,52,57,69,73,74,90}$ \\
Cross-sectional (descriptive design) & $8^{42,49,59,60,66,68,70,75}$ \\
Longitudinal study & $8^{43,45,50,53,54,64,77,85}$ \\
Twin study & $2^{72,76}$ \\
Randomized controlled study & $8^{46,47,51,56,58,61,63,71}$ \\
\hline
\end{tabular}

in other two articles, ${ }^{57,68}$ and with the Hedonic and Eudaimonic Motives for Activities $^{3}$ in other two articles. ${ }^{69,70}$

Table 3 Instruments used to assess eudaimonia and depression

\begin{tabular}{|c|c|}
\hline Measures of eudaimonia & Number of articles \\
\hline Psychological Well-being scale - PWB ${ }^{1}$ & $13^{42-54}$ \\
\hline Mental Health Continuum $(\mathrm{MHC})^{56}$ & $6^{56-61}$ \\
\hline Meaning in Life Questionnaire (MLQ) ${ }^{9}$ & $2^{48,64}$ \\
\hline Flourishing Scale ${ }^{62}$ & $2^{51,63}$ \\
\hline Eudaimonic and Hedonic Happiness & $2^{57,68}$ \\
\hline Investigation $(\mathrm{EHHI})^{67}$ & \\
\hline Pemberton Happiness Index ${ }^{65}$ & $2^{47,66}$ \\
\hline $\begin{array}{l}\text { Hedonic and Eudaimonic Motives for } \\
\text { Activities (HEMA })^{4}\end{array}$ & $2^{69,70}$ \\
\hline $\begin{array}{l}\text { Adolescents Eudaimonic Behavior - } \\
\text { Social Capital }\end{array}$ & $1^{77}$ \\
\hline $\begin{array}{l}\text { Balanced Measure of Psychological } \\
\text { Needs (BMPN) }\end{array}$ & $1^{71}$ \\
\hline Basic Psychological Needs Scale ${ }^{80}$ & $1^{57}$ \\
\hline Cantril Ladder ${ }^{82}$ & $1^{76}$ \\
\hline COMPAS-W of well-being ${ }^{80}$ & $1^{72}$ \\
\hline Elevation Experience Scale ${ }^{3}$ & $1^{73}$ \\
\hline Orienation to happiness ${ }^{\prime \prime}$ & $\mathrm{I}^{74}$ \\
\hline $\begin{array}{l}\text { Questionnaire for Eudaimonic Well- } \\
\text { being }^{7}\end{array}$ & $1^{52}$ \\
\hline Warwick-Edinburgh Mental Well-being ${ }^{81}$ & $1^{75}$ \\
\hline \multicolumn{2}{|l|}{ Measures of depression } \\
\hline Depression Anxiety Stress Scale - DASS ${ }^{84}$ & $\left.1\right|^{42,44,49,59,63,68,69,72,73,77,85}$ \\
\hline $\begin{array}{l}\text { Centers for Epidemiological Studies - } \\
\text { Depression (CES-D) }\end{array}$ & $10^{48,50,52,54,56,58,61,64,74,75}$ \\
\hline $\begin{array}{l}\text { Hospital Anxiety and Depression Scales } \\
(\text { HADS })^{87}\end{array}$ & $4^{51,58,60,70}$ \\
\hline Beck Depression Inventory ${ }^{88}$ & $3^{47,53,71}$ \\
\hline Edinburgh Postnatal Depression ${ }^{89}$ & $2^{43,45}$ \\
\hline Anxiety and Depression Subscale & $1^{76}$ \\
\hline Achenbach System of Empirical-based & \\
\hline Assessment $^{91}$ & \\
\hline Clagary Depression Scale ${ }^{92}$ & $I^{46}$ \\
\hline $\begin{array}{l}\text { Behavior Activation for Depression } \\
\text { Scale }^{93}\end{array}$ & $1^{61}$ \\
\hline Major Depressive Inventory ${ }^{94}$ & $1^{66}$ \\
\hline Patient Health Questionnarie ${ }^{95}$ & $1^{90}$ \\
\hline
\end{tabular}

Other nine articles ${ }^{52,57,71-77}$ assessed eudaimonia with nine additional instruments: the Balanced Measure of Psychological Needs, ${ }^{78}$ the Basic Psychological Needs Scale,${ }^{79}$ the COMPAS-W of well-being, ${ }^{80}$ the Elevation Experience Scale ${ }^{3}$ the Orientation to Happiness Scale, ${ }^{11}$ the Questionnaire for Eudaimonic Well-being, ${ }^{7}$ the Warwick Edinburgh mental well-being scale, ${ }^{81}$ the Cantril Ladder scale, ${ }^{82}$ and the Adolescents Eudaimonic Behavior, ${ }^{83}$ respectively.

In conclusion, eudaimonia was assessed with 16 different quantitative measures, being Ryff's PWB and Keyes's MHC the most frequently used (see Table 3).

\section{Instruments for assessing depression}

Table 3 indicates the quantitative measures used for evaluating depression. The most used one was the Depression Anxiety and Stress Scale (DASS) ${ }^{84}$ which was applied in $11^{42,44,49,59,63,68,69,72,73,77,85}$ of 34 studies. DASS was used in its complete version or by selecting only the depression subscale. ${ }^{44}$ The second most used quantitative measure of depression was the Center for Epidemiological Studies Depression Scale (CES-D), ${ }^{86}$ which was used in ten investigations. ${ }^{48,50,52,54,56,58,61,64,74,75}$

Depression was also measured with the Hospital Anxiety and Depression Scale (HADS) ${ }^{87}$ in four articles, ${ }^{51,58,60,70}$ with Beck Depression Inventory ${ }^{88}$ in three articles, ${ }^{47,53,71}$ with the Edinburgh Postnatal Depression Scale ${ }^{89}$ in two articles. ${ }^{43,45}$

Other five articles ${ }^{46,61,66,76,90}$ assessed depression with Anxiety and Depression Subscale of the Achenbach System of Empirical-based Assessment, ${ }^{91}$ with the Calgary Depression Scale, ${ }^{92}$ with the Behavior Activation for Depression Scale, ${ }^{93}$ with the Major Depressive Inventory ${ }^{94}$ and with the Patient Health Questionnaire, ${ }^{95}$ respectively.

In conclusion, depression was assessed with 10 different quantitative measures (see Table 3).

\section{Populations included}

Table 4 summarizes the type and the total number of participants evaluated in the 34 selected articles. The populations included ranged from adults within the general and clinical populations, to college/ university students, to adolescents and to young adults entering adulthood. A total of 81,987 individuals were included.

\section{Twin studies}

Almost half of the total sample was recruited in two twin studies, ${ }^{72,76}$ aimed at investigating the genetic underpinning of EWB and depression/negative affectivity. The first 
Table 4 Populations evaluated in eudaimonia and depression

\begin{tabular}{|l|l|l|}
\hline Type of populations & Number of articles & Number of individuals \\
\hline Twins & $2^{72,76}$ & 44,913 \\
Young populations, college, or university students & $10^{44,48,49,52,59,61,64,69,73,77}$ & 19,415 \\
Adult, general populations & $14^{3,5,42,45,50,51,54,57,60,70,74,75,84}$ & 17,429 \\
Adult clinical populations (anxiety, depressive disorders, and eating psychotic disorders) & $8^{46,47,53,56,63,71,85,90}$ & 1436 \\
Total number of individuals & & 81,987 \\
\hline
\end{tabular}

study $^{76}$ had a longitudinal design and was focused on examining the association between EWB and depression across the lifespan in 43,427 twins. It was found that EWB and depressive symptoms were significantly correlated and the correlation increased with age, ranging from -0.34 during childhood to -0.49 in adulthood, with the highest correlations in young adults $(-0.57)$. Bivariate twin models revealed that shared environmental factors played an important role in explaining the relationship between eudaimonic well-being and depressive symptoms in childhood, while in adolescence and adulthood genetic factors became increasingly important.

Similarly, Routledge et $\mathrm{al}^{72}$ found that genetic factors contributed to about half of the phenotypic correlation between depression and anxiety symptoms and wellbeing (ie, 56.34\%) in a sample of 1486 Australian twins who were classified into the normative levels of depression. However, authors found that two-thirds of the total variance in EWB scores was completely distinct from anxiety and depression, as measured with the DASS. Authors suggested that the majority of genetic and environmental factors influencing EWB do not impact anxiety and depressive symptoms. Moreover, authors also found a gap between the assessment of distress and the presence of optimal well-being: $93 \%$ of their twin participants were classified into the normal range of symptoms, but only $23 \%$ of them were also classified as "flourishing" on the COMPAS-W well-being scale. ${ }^{80}$ Authors concluded that both unique and shared genetic and environmental factors may determine why some individuals flourish in the absence of symptoms, while others do not.

\section{Young populations, college, and university students}

The second large category of population included in the present review is the one composed by college and university students. Ten different investigations focused on this category. The one including most of the college students $^{48}(\mathrm{~N}=8492)$ assessed eudaimonia with Ryff's scale, ${ }^{1}$ together with Meaning in Life Questionnaire, ${ }^{9}$ and depression was measured with the CES-D. ${ }^{86}$ College students were classified into five clusters, according to the different combination of the presence of meaning in life versus search for meaning. Individuals in the High Presence-Low Search cluster reported the highest levels of positive psychosocial functioning, as well as the lowest levels of depression. Meaning in life was measured in another investigation ${ }^{64}$ with 744 American college students. Also in this case, meaning in life was strongly associated with purpose in life and with depression. Importantly, authors found that religiosity was an important source of meaning and emphasized its role for promoting eudaimonia.

On the same vein, Kryza et al ${ }^{69}$ applied a classification of 119 undergraduate students based on their levels of eudaimonia in order to predict academic achievements and negative emotional states. Authors used the HEMA measure $^{3}$ for identifying four groups of students: the Full Life group (scores at or above the median on both Hedonia and Eudaimonia scales), the Eudaimonia Life group (scores at or above the median on Eudaimonia, but below the median on Hedonia), the Hedonic Life group (scores below the median on Eudaimonia, but at or above the median on Hedonia), Empty Life group (scores below the median on both Hedonia and Eudaimonia scales). Individuals in the Full Life group had higher academic performance compared to students with low Eudaimonia. Eudaimonia was also significantly negatively associated with depression and stress, measured with the DASS questionnaire. $^{84}$

Similarly, Bhullar et $\mathrm{al}^{44}$ aimed at classifying 207 Australian university students in 5 clusters, according to their levels of EWB, ranging from low to very high levels in all Ryff's six domains. ${ }^{1}$ Thirty percent of the sample exhibited high and very high levels on all six indicators of PWB, and they had also lower levels of depression, compared to individuals classified in low profile of EWB.

Another group of 88 Australian university students ${ }^{49}$ was assessed with Ryff's scale ${ }^{1}$ and with $\mathrm{DASS}^{84}$ and was 
compared to a matched group of British students. No significant differences emerged between these groups, but eudaimonia was consistently and negatively correlated to depression in both groups.

Another Canadian investigation ${ }^{73}$ confirmed the inverse correlations between eudaimonia and depression in 121 undergraduate students. In this case, the authors ${ }^{73}$ aimed at demonstrating the beneficial effect of nature on mental health. Three different experiments showed that the conditions of virtual and real contact with nature increased EWB and decreased depression (measured with the DASS).

Another study ${ }^{61}$ assigned 94 university students with mild to moderate depression to different treatment conditions based on homework assignment, including standard CBT or a positive psychology intervention. Homework assignments based on CBT and positive psychology were equally effective in reducing depressive symptoms and increasing EWB, compared to a waiting list (WL) control group.

Finally, the other investigation with a large multiethnic sample of college students $(\mathrm{N}=8020)$ aimed at examining the relationship between sensation seeking and eudaimonia. ${ }^{52}$ Female gender and low depressive symptoms were associated with eudaimonia, which was associated with high novelty seeking. However, novelty seeking was manifested with a low-intensity pattern, which was not correlated to risky behavior.

Eudaimonia was also assessed in two studies involving young populations, not recruited in college institutions. The first $^{59}$ one included 539 Indian adolescents and found that $46.4 \%$ of the participants were flourishing, $51.2 \%$ were moderately mentally healthy, and only $2.4 \%$ were languishing. The flourishing Indians reported lower prevalence of depression and more prosocial behaviors. The second study ${ }^{77}$ included a large cohort of Australians ( $=991)$ and, with a prospective design, it was found that eudaimonia was not directly related to the development of anxious-depressive symptoms. Rather, authors (Hallam et al) ${ }^{77}$ suggested that eudaimonia in adolescence may indirectly reduce the risk for anxious-depressive symptoms by promoting emotional competence across emerging adulthood.

In conclusions, eudaimonia and depression were found to be negatively correlated in young populations, and college/university students. In these age populations, the presence of high levels of eudaimonia was found to be predictive of higher academic success, of higher meaning in life, lower distress and lower risky behaviors. Furthermore, traditional CBT interventions, psychological interventions based on positive psychology or based on the contact with nature were found to be effective either in addressing depression or in promoting eudaimonia.

\section{Adult general populations}

Fourteen studies evaluated EWB and depression in the general population, including a total of 17,429 individuals.

In the largest one, ${ }^{50}$ a cohort of 10,317 individuals recruited in the Wisconsin Longitudinal Study was evaluated in terms of eudaimonia, depression, and personality dimensions. Over time, personality change was more strongly related to change in eudaimonia than changes in other indicators, such as depression, hostility, and life satisfaction.

In another large, international study ${ }^{74} 3690$ participants were recruited in 7 different countries, and they were classified into 4 clusters, according to their levels of eudaimonia. Authors used the Orientation to Happiness questionnaire $^{11}$ in order to classify individuals into the Full, Empty, Pleasurable, and Meaningful life groups. In all seven countries, individuals classified into the Full Life type reported the highest PWB, the highest life satisfaction, and the lowest depressive symptoms, compared to individuals in the Empty life, who reported the highest depressive symptoms and the lowest well-being.

Another cross-sectional study ${ }^{57}$ found that eudaimonia was associated with meaning in life in a sample of 247 individuals from New Zealand. In particular, family was the most important source of meaning in life, followed by interpersonal relationships, personal growth, and work.

In other three investigations, eudaimonia and depression were associated with materialism, ${ }^{66}$ self-compassion, ${ }^{60}$ and with ego strengths and with the use of specific defense mechanisms. ${ }^{54}$ In the first case, ${ }^{66}$ eudaimonia and depressive symptoms were measured in a group of 327 Spanish individuals. Those participants with lower explicit materialism reported more EWB and less depressive symptoms. The second study ${ }^{60}$ found that the relationship between EWB (measured with the $\mathrm{MHC}^{55}$ ) and depression was mediated by participants' $(\mathrm{N}=349)$ levels of self-compassion. Accordingly, individuals with high levels of positive mental health possessed self-compassion skills that promoted resilience against psychopathology (measured with the HADS). The third study, ${ }^{54}$ which included more than 400 participants, found that depression and EWB dimensions were inversely correlated and correlated to the use of specific defense mechanisms. Eudaimonic well-being dimensions were significantly associated with the use of 
more mature defenses and with higher ego strengths. Importantly, over a 6-year time, it was found that more mature defenses and high ego strength at baseline predicted increases in EWB, but not changes in depression. These findings suggest an important difference between EWB and depression in long-term outcomes.

Two studies examined eudaimonia and depression during the transition to parenthood. The first one ${ }^{43}$ focused on 81 mothers and distinguished primiparous from multiparous. Their levels of depressive symptoms did not differ, nor did they change after childbirth. By contrast, after childbirth, primiparous women reported higher environmental mastery and self-acceptance than multiparous women. The second investigation ${ }^{45}$ focused on 50 fathers and found that their levels of eudaimonia increased after childbirth, more than those of mothers. However, at postpartum, EWB was largely predicted by pre-natal levels in both parents.

Two other studies examined two other features related to eudaimonia and depression in midlife, namely the cognitive reserve ${ }^{42}$ and the menopausal symptoms. ${ }^{75}$ In the first case, it was found that a better cognitive status was associated with a lower age, the male gender, and higher EWB in 1081 participants. Conversely, negative affectivity, including depression, anxiety, and stress, only showed an association with eudaimonia, but not with cognitive reserve or cognitive functioning. The second study $^{75}$ included a sample of 206 Australian women assessed with the Warwick Edinburgh mental well-being ${ }^{81}$ and the CES-D. ${ }^{86}$ Psychological aspects of the menopause appeared more strongly linked to EWB than physiological aspects (such as menopausal stage and hot flush frequency). No evidence was found of a link between menopausal stage and depressive symptoms in the sample. The dimension of self-compassion was strongly associated with EWB also in this sample.

Other two studies associated eudaimonia and depression with providing help and support to others, either as a caregiver, or as a member of helping professions. The first study ${ }^{68}$ found that 91 caregivers with high burden reported higher levels of depression, lower life satisfaction, and lower resilience. Life satisfaction and resilience were also found to predict perceived burden. The second study ${ }^{70}$ involved 99 staff members of organizations providing professional help for autistic patients. The authors studied their levels of motivation with the HEMA and found that eudaimonic motivation significantly reduced the likelihood of anxiety while it also predicted higher life satisfaction.
However, depression was not predicted by eudaimonic motivation. The authors recommended to test the effect of interventions in promoting eudaimonic motivation in these staff members, since they may help their assisted patients in framing psychological distress as an opportunity for personal development.

Finally, two Randomized Controlled Trial (RCT) studies evaluated the impact of a positive self-help intervention $^{51}$ and of a community mindfulness intervention $^{58}$ in promoting EWB and improving psychological distress in non-clinical samples. The first one ${ }^{51}$ showed that a 9-week positive intervention improved the proportion of flourishing individuals $(\mathrm{N}=275)$ from $7 \%$ to $30 \%$ after 3 months and to $34 \%$ after 6 months. The second study ${ }^{58}$ demonstrated significant reductions in depression, anxiety, and improvements in mindfulness and mental health in participants $(\mathrm{N}=151)$ treated with a mindfulness group intervention. Importantly, these improvements were maintained at follow-up.

In conclusions, the 14 articles focused on adult general populations found that eudaimonia and depression are inversely correlated. They also showed different pattern of correlations with personality factors, defense mechanisms, materialism, and cognitive reserve, among others. Eudaimonia and depression were found to be related to specific phases of life, such as becoming a parent or entering menopause. Self-compassion, resilience, and meaning in life presented a high influence on eudaimonia and in some cases, they also mediated the relationship between eudaimonia and depression.

\section{Adult clinical populations}

Eight investigations focused on clinical populations: four are RCT, ${ }^{47,56,63,71}$ three ${ }^{46,53,85}$ have a longitudinal design (pre-post intervention assessments), and one ${ }^{90}$ is crosssectional. Eudaimonia and depression were assessed in 1436 individuals reporting mild to moderate depression or dysthymia, affective disorders (anxiety and depression), anxiety disorders, non-affective psychosis, or eating disorders. Most of these clinical trials relied on the concept of "mental health continuum",55,97 where psychopathology and EWB have a reciprocal influence. Hence, targeting one may result in beneficial effect on the other, or viceversa.

Four investigations were explicitly focused on patients with depressive disorders and they all are RCT. Chaves ${ }^{47}$ compared the efficacy of a positive psychology interventionwith a traditional CBT in 96 patients with major 
depressive disorder or dysthymia and found that both interventions were effective in reducing psychopathology and increasing positive functioning. However, there were no significant differences in terms of depressive symptoms, nor EWB dimensions between the two treatments. In a subsequent analyses, ${ }^{96}$ authors documented that the only significant difference between conditions was client satisfaction, which was higher in the Positive Psychology Intervention (PPI) group. Similarly, Quitasol ${ }^{71}$ applied a protocol of CBT and compared its efficacy with standard antidepressant treatment in a sample of 51 depressed patients, whose psychological needs fulfillment was observed over the course of treatment. Authors found that they did not differ significantly between treatment conditions, but increases in need fulfillment during treatment were associated with decreases in depression severity. Authors suggested to dedicate more attention to the dimension of psychological need fulfillment in the treatment of depression. On the other hand, Bohlmeijer et $\mathrm{al}^{56}$ and de Manincor et $\mathrm{al}^{63}$ applied new forms of treatment for depressive patients and compared them to a WL condition. Bohlmeijer et $\mathrm{al}^{56}$ aimed at evaluating the impacts of a guided self-help intervention based on acceptance and commitment therapy (ACT) on promoting flourishing, measured with MHC in a sample of 376 individuals. The study found that in the ACT condition, almost $30 \%$ of the participants were flourishing, whereas this percentage was about $14 \%$ for participants in the WL. From baseline to post-intervention, $24 \%$ of the participants improved from not-flourishing to flourishing in the ACT condition, as compared to $10.3 \%$ in the WL condition. In the ACT condition, the predictors of flourishing at post-intervention were: higher level of positive mental health at baseline, lower levels of depressive symptoms at baseline along with a larger decrease in depressive symptoms during the intervention, and larger increases in psychological flexibility during the intervention. Authors suggested that ACT targets both underlying factors of psychopathology and factors of EWB and flourishing (eg, value clarification and goal-setting). Similarly, de Manincor et $\mathrm{al}^{63}$ found that a 6-week individualized yoga intervention significantly reduced depressive symptoms and promoted flourishing and resilience in 101 depressed patients, when compared to WL. However, these differences between treatment conditions disappeared after 6 weeks.

With a cross-sectional design, Seow et al ${ }^{90}$ analyzed the clinical and sociodemographic variables associated with positive mental health in a group of patients with depressive and anxiety disorders $(\mathrm{N}=2018)$. The study revealed that positive mental health was significantly associated with life satisfaction and general functioning even after controlling for sociodemographic and clinical variables. Emotional support was found to have a role on depressive symptoms. A younger age with early onset of the disorders was associated with lower positive mental health. However, authors reported a higher variability in positive mental health in this group of outpatients, and these data confirmed the dual model continuum of mental health. ${ }^{97}$

Similarly, Teisman et $\mathrm{al}^{85}$ measured positive mental health in a sample of 130 patients with various anxiety disorders (phobias, panic attack, agoraphobia) and found that it was the only significant predictor of post-treatment symptom severity and remission status. Authors also applied a longitudinal evaluation and found that post-treatment positive mental health predicted symptom severity and remission status 6 months after treatment termination. The second longitudinal study ${ }^{46}$ aimed at evaluating the relationship between eudaimonia and recovery in a sample of 404 patients with psychosis. Authors found that the duration of untreated psychosis was associated with the dimensions of positive relationships and environmental mastery. Active treatment (compared to community care) significantly improved eudaimonia and triggered recovery in psychotic patients. Lastly, with another longitudinal design, Tecuta and Tomba ${ }^{53}$ evaluated EWB and depressive symptoms in a sample of 60 outpatients with eating disorders treated with CBT. Changes in depressive symptoms and in subjective incompetence predicted improvements in EWB, particularly in the dimensions of environmental mastery, purpose in life, and self-acceptance.

In conclusions, depression and eudaimonia were found to be inversely correlated in clinical populations. In these groups, the two variables were mostly studied during the course of interventions, including pharmacotherapy or psychotherapy. The treatments applied to address depression and eudaimonia were ACT, CBT, or PPT. Across studies, baseline levels of eudaimonia were significant predictors of recovery, relapse, or flourishing at postinterventions.

\section{Discussion}

The aim of the present systematic review was to provide an updated summary of articles that evaluated eudaimonia together with depressive symptoms. These issues have been previously investigated, and it was found that 
eudaimonia could have a protective role for mental health, and that its absence was found to be a risk factor for developing depression. ${ }^{28}$ However, previous literature also highlighted the paucity of studies involving clinical populations, and the heterogeneity of assessment tools used to evaluate eudaimonia. ${ }^{30}$ Furthermore, it was found that interventions aimed at addressing depression also promoted eudaimonia. ${ }^{18,98}$ On the other hand, positive interventions focused on promoting eudaimonia were found to yield benefits to depressive symptoms. ${ }^{35,99}$ Another relatively new field of investigation is the common biological or genetic underpinnings that the two phenomena may share. ${ }^{14}$ Studies on all these issues did not reach definitive conclusions, yet.

The present review provides a first effort in order to address them, by analyzing published works in the recent scientific literature (over the past 5 years). We identified 34 articles, with a total of 81,987 participants (including adolescents/young adults and middle-aged individuals). Eight articles included clinical populations, presenting mood, anxiety, eating, and psychotic disorders. Two large, twin studies examined the genetic underpinnings of eudaimonia and depression, four studies examined eudaimonia and depression in peculiar life stages, such as adolescence, middle age, or during the transition to parenthood. Another large number of articles included young populations recruited in college/university settings. Thus, a first observation that could be drawn is that this review addresses previous limitations of the literature by exploring eudaimonia and depression in a variety of populations, including large clinical samples.

Eudaimonia was assessed mainly with the Ryff's PWB scale, ${ }^{1}$ followed by the MHC. ${ }^{55}$ Interestingly, MHC shares the same conceptual framework of the PWB, with six items of 14 derived directly from PWB. However, the specific advantage of using MHC relied on the possibility of categorizing individuals as languishing or flourishing according to specific criteria and scores. Eudaimonia, in this case, was conceived as a state of flourishing, or a state of positive mental health. ${ }^{55}$ In any case, the state of flourishing was almost consistently associated with lower levels of depression or a better recovery after clinical interventions. ${ }^{56,60}$ Thus, the use of flourishing diagnoses might provide clinicians a more comprehensive understanding of an individual's mental health, or it may be used as an indicator of recovery after clinical interventions. ${ }^{55}$

However, other investigations used different models for conceptualizing eudaimonia, such as need fulfillment, ${ }^{3}$ orientation to happiness, ${ }^{11}$ or meaning in life, ${ }^{9}$ among others. Accordingly, individuals were categorized in different groups, such as belonging to the Full Life group, or the Eudaimonia Life group, or to the Presence of Meaning group. In any case, the results are similar across all these investigations: individuals belonging to those categories presented lower levels of depression compared to those classified into the Empty Life group, the Hedonic Life group, or the search for meaning group. Thus, these results provide confirmation to the inverse relationship between eudaimonia and depression. They also confirm the protective role of eudaimonia for mental health, across the population examined (clinical, adults, college students, etc.).

On a different level, these results also confirm the existing heterogeneity of definitions of eudaimonia and the use of different assessment instruments for its evaluation. ${ }^{30}$ Depression was similarly assessed with eight different tools, being the DASS ${ }^{84}$ the most frequently applied across the 34 studies. Unfortunately, most of the investigations assessed depression by self-report measures only, and this may limit the clinical sensitivity of the evaluation. However, the definition and the clinical characteristics of depression are well established by pre-existing clinical research. In order to be able to generalize and replicate findings on eudaimonia and its association with depression, it would be recommendable to reach for a larger consensus on the definition of eudaimonia and on its most appropriate instrument(s) of assessment.

Beyond its protective role for mental health, EWB has been recently investigated in its biological and/or genetic underpinnings, which might explain its influence on physical health as well. ${ }^{14-16}$ Two twin studies ${ }^{72,76}$ in the present review confirmed the impact of genetic variables in determining the correlations between EWB and depression. These two studies did not assess the CTRA response. ${ }^{14}$ However, these studies ${ }^{72,76}$ included large samples and they identified different patterns of genetic influence across life stages and between different groups of individuals, ranging from $1 / 3$ of common genetic factors to almost $50 \%$. In spite of this, both studies ${ }^{72,76}$ concluded by emphasizing the role of environmental factors - which become particularly important in late adulthood - for explaining most of the variability and for identifying individuals who flourish from those who do not. A better understanding of the common biological underpinnings between depression and eudaimonia is a necessary purpose for future research. 
Finally, this review summarized different interventions which were found to be effective in promoting eudaimonia and in addressing depression. These interventions ranged from traditional clinical approaches - such as pharmacotherapy or cognitive-behavioral treatment $-{ }^{61}$ to third-generation psychotherapies - such as Acceptance and Commitment Therapy ${ }^{56}$ or Mindfulness $-{ }^{58}$ to newly developed interventions, derived from the positive psychology perspective (ie, positive psychotherapy) ${ }^{47}$ Interventions also included mindbody approaches, such as yoga therapy ${ }^{63}$ or contact with nature. ${ }^{73}$ When compared to WT or to controlled conditions, these interventions were found to be more effective, and generally they were appreciated by participants. ${ }^{96}$ Thus, clinicians, counselors, and practitioners can select different strategies to promote EWB and to address depressive symptoms, according to participants' clinical status, or best preference.

Despite the updated findings reported by this review, it has also some limitations. First of all, it is possible that we may have missed in-press articles or articles not written and published in English, since research on EWB is rapidly expanding all over the world. Hence, it is to be expected that a larger number of studies will be available at a future point. Furthermore, this investigation included instruments that only measured EWB together with measures of depression. Thus, articles designed to assess other dimensions of well-being (eg, life satisfaction, positive emotions, subjective well-being, etc.) or other elements (ie, only meaning in life or resilience) were not regarded. Even though we are aware that these dimensions of positive functioning may present important relationships with depression, we opted to select measures of EWB in order to derive a more specific pattern of correlation with depression. Similarly, we excluded articles pertaining to eudaimonia and depression in older adults. Considering the important roles of these two dimensions in influencing aging processes, future review articles should address eudaimonia and depression in this specific population.

In conclusion, this review highlights the need for future research to reach more consensus on the definition of eudaimonia and on the specific measure(s) to evaluate it in different populations and in different life stages, ranging from children to middle age. Importantly, this review confirms the inverse correlations between eudaimonia and depression, and thus, its crucial role in clinical and developmental settings. As a consequence, the presence of EWB should be monitored longitudinally across different life stages, particularly when existential changes may occur (ie, from adolescence to adulthood, or during the transition to parenthood, or when entering middle age and retirement). Finally, findings of this review suggested that EWB could be promoted by different interventions, and its presence should be considered as a key clinical indicator of recovery from depression or from other mental disorders.

\section{Disclosure}

The authors have no conflicts of interest to declare in this work.

\section{References}

1. Ryff CD. Happiness is everything, or is it? Explorations on the meaning of psychological well-being. J Pers Soc Psychol. 1989;57 (6):1069-1081. doi:10.1037/0022-3514.57.6.1069

2. Ryff CD. Psychological well-being revisited: advances in the science and practice of eudaimonia. Psychother Psychosom. 2014;83(1):1028. doi:10.1159/000353263

3. Huta V, Ryan RM. Pursuing pleasure or virtue: the differential and overlapping well-being benefits of hedonic and eudaimonic motives. J Happiness Stud. 2010;11(6):735-762. doi:10.1007/s10902-0099171-4

4. Huta V, Waterman AS. Eudaimonia and its distinction from hedonia: developing a classification and terminology for understanding conceptual and operational definitions. J Happiness Stud. 2014;15 (6):1425-1456. doi:10.1007/s10902-013-9485-0

5. Diener E, Emmons RA, Larsen RJ, Griffin S. The satisfaction with life scale. J Pers Assess. 1985;49(1):71-75. doi:10.1207/ s15327752jpa4901_13

6. Diener E, Heintzelman SJ, Kushlev K, et al. Findings all psychologists should know from the new science on subjective well-being. Can Psychol. 2017;58(2):87-104. doi:10.1037/cap0000063

7. Waterman AS, Schwartz SJ, Zamboanga BL, et al. The questionnaire for eudaimonic well-being: psychometric properties, demographic comparisons, and evidence of validity. J Posit Psychol. 2010;5 (1):41-61. doi:10.1080/17439760903435208

8. Ryan RM, Huta V, Deci EL. Living well: a self-determination theory perspective on eudaimonia. J Happiness Stud. 2008;9(1):139-170. doi:10.1007/s10902-006-9023-4

9. Steger MF, Frazier P, Kaler M, Oishi S. The meaning in life questionnaire: assessing the presence of and search for meaning in life. $J$ Couns Psychol. 2006. doi:10.1037/0022-0167.53.1.80

10. Deci EL, Ryan RM. The general causality orientations scale: selfdetermination in personality. $J$ Res Pers. 1985;19:109-134. doi:10.1016/0092-6566(85)90023-6

11. Peterson C, Park N, Seligman MEP. Orientations to happiness and life satisfaction: the full life versus the empty life. J Happiness Stud. 2005;6(1):25-41. doi:10.1007/s10902-004-1278-z

12. Kim ES, Kawachi I, Chen Y, Kubzansky LD. Association between purpose in life and objective measures of physical function in older adults. JAMA Psychiatry. 2017;74(10):1039-1045. doi:10.1001/ jamapsychiatry.2017.2145

13. Boyle P, Buchman A, Wilson R, Yu L, Schneider J, Bennett DA. Effect on purpose of life on the relation between alzheimer disease pathologic changes on cognitive function in advanced age. Arch Gen Psychiatry. 2012;69(5):499-505. doi:10.1001/archgenpsychiatry.2011.1487.Effect

14. Cole SW, Levine ME, Arevalo JMG, Ma J, Weir DR, Crimmins EM. Loneliness, eudaimonia, and the human conserved transcriptional response to adversity. Psychoneuroendocrinology. 2015;62:11-17. doi:10.1016/j.psyneuen.2015.07.001 
15. Fredrickson BL, Grewen KM, Coffey KA, et al. A functional genomic perspective on human well-being. Proc Natl Acad Sci U S A. 2013;110(33):13684-13689. doi:10.1073/pnas.1305419110

16. Nelson-Coffey SK, Fritz MM, Lyubomirsky S, Cole SW. Kindness in the blood: a randomized controlled trial of the gene regulatory impact of prosocial behavior. Psychoneuroendocrinology. 2017. doi:10.1016/ j.psyneuen.2017.03.025

17. Ryff CD, Singer B. Psychological well-being: meaning, measurement, and implications for psychotherapy research. Psychother Psychosom. 1996;65(1):14-23. doi:10.1159/000353263

18. Fava GA, Ruini C, Rafanelli C, Finos L, Conti S, Grandi S. Six-year outcome of cognitive behavior therapy for prevention of recurrent depression. Am J Psychiatry. 2004;161(10):1872-1876. doi:10.1176/ appi.ajp.161.10.1872

19. Fava GA, Ruini C, Rafanelli C. Sequential treatment of mood and anxiety disorders. $J$ Clin Psychiatry. 2005;66(11):1392-1400. doi:10.4088/JCP.v66n1108

20. Ruini C, Albieri E, Vescovelli F. Well-being therapy: state of the art and clinical exemplifications. J Contemp Psychother. 2015;45 (2):129-136. doi:10.1007/s10879-014-9290-z

21. Moeenizadeh M, Salagame KKK. The impact of well - being therapy on symptoms of depression. Int J Psychol Stud. 2010;2(2):223-230. Available from: http://search.proquest.com/docview/840751673?accoun tid $=35812$.

22. Ryff CD, Keyes CL. The structure of psychological well-being revisited. $J$ Pers Soc Psychol. 1995;69(4):719-727. doi:10.1037/00223514.69.4.719

23. Friedman EM, Ruini C, Foy R, Jaros L, Sampson H, Ryff CD. Lighten UP! A community-based group intervention to promote psychological well-being in older adults. Aging Ment Heal. 2017;21 (2):199-205. doi:10.1080/13607863.2015.1093605

24. Cesetti G, Vescovelli F, Ruini C. The promotion of well-being in aging individuals living in nursing homes: a controlled pilot intervention with narrative strategies. Clin Gerontol. 2017;40 (5):07317115.2017.1292979. doi:10.1080/07317115.2017.1292979

25. Ruini C, Belaise C, Brombin C, Caffo E, Fava GA. Well-being therapy in school settings: a pilot study. Psychother Psychosom. 2006;75(6):331-336. doi:10.1159/000095438

26. Ruini C, Ottolini F, Tomba E, et al. School intervention for promoting psychological well-being in adolescence. $J$ Behav Ther Exp Psychiatry. 2009;40(4):522-532. doi:10.1016/j.jbtep.2009.07.002

27. Ruini C, Vescovelli F, Carpi V, Masoni L. Exploring psychological well-being and positive emotions in school children using a narrative approach. Indo-Pacific J Phenomenol. 2017;17(1):1-9. doi:10.1080/ 20797222.2017.1299287

28. Wood AM, Joseph S. The absence of positive psychological (eudemonic) well-being as a risk factor for depression: a ten year cohort study. $J$ Affect Disord. 2010;122(3):213-217. doi:10.1016/j. jad.2009.06.032

29. Knight T, Davison TE, Mccabe MP, Mellor D. Environmental mastery and depression in older adults in residential care. Ageing Soc. 2011;31(5):870-884. doi:10.1017/S0144686X1000142X

30. Brandel M, Vescovelli F, Ruini C. Beyond Ryff's scale: comprehensive measures of eudaimonic well-being in clinical populations. A systematic review. Clin Psychol Psychother. 2017;24:o1524-o1546. doi:10.1002/cpp.2104

31. Gotlib IH, Joormann J. Cognition and depression: current status and future directions. Annu Rev Clin Psychol. 2010;6:285-312. doi:10.1146/annurev.clinpsy.121208.131305

32. McMakin DL, Santiago CD, Shirk SR. The time course of positive and negative emotion in dysphoria. J Posit Psychol. 2009. doi:10.1080/17439760802650600

33. Dunn BD, Stefanovitch I, Buchan K, Lawrence AD, Dalgleish T. A reduction in positive self-judgment bias is uniquely related to the anhedonic symptoms of depression. Behav Res Ther. 2009;47 (5):374-381. doi:10.1016/j.brat.2009.01.016
34. Bolier L, Haverman M, Westerhof GJ, Riper H, Smit F, Bohlmeijer E. Positive psychology interventions: a meta-analysis of randomized controlled studies. BMC Public Health. 2013;13:1. doi:10.1186/14712458-13-119

35. Weiss LA, Westerhof GJ, Bohlmeijer ET. Can we increase psychological well-being? The effects of interventions on psychological well-being: a meta-analysis of randomized controlled trials. PLoS One. 2016;11(6):e0158092. doi:10.1371/journal.pone.0158092

36. Rashid T. Positive psychotherapy: a strength-based approach. J Posit Psychol. 2015;10(1):25-40. doi:10.1080/17439760.2014.920411

37. Seligman MEP, Rashid T, Parks AC. Positive psychotherapy. Am Psychol. 2006;61(8):774-788. doi:10.1037/0003-066X.61.8.774

38. Rafanelli C, Park SK, Ruini C, Ottolini F, Cazzaro M, Fava GA. Rating well-being and distress. Stress Med. 2000;16:1. doi:10.1002/ (SICI)1099-1700(200001)16:1<55::AID-SMI832>3.0.CO;2-M

39. Ruini C, Ottolini F, Rafanelli C, Tossani E, Ryff CD, Fava GA. The relationship of psychological well-being to distress and personality. Psychother Psychosom. 2003;72(5):268-275. doi:10.1159/000071898

40. Fava GA, Ruini C, Belaise C. The concept of recovery in major depression. Psychol Med. 2007;37(3):307-317. doi:10.2975/30.3.2007.171.173

41. Moher D, Liberati A, Tetzlaff J, et al. Preferred reporting items for systematic reviews and meta-analyses: the PRISMA statement (Chinese edition). J Chinese Integr Med. 2009;7(9):889-896. doi:10.3736/jcim20090918

42. Bartrés-Faz D, Cattaneo G, Solana J, Tormos JM, Pascual-Leone A. Meaning in life: resilience beyond reserve. Alzheimer's Res Ther. 2018;10:1. doi:10.1186/s13195-018-0381-z

43. Bassi M, Delle Fave A, Cetin I, et al. Psychological well-being and depression from pregnancy to postpartum among primiparous and multiparous women. J Reprod Infant Psychol. 2017;35(2):183-195. doi:10.1080/02646838.2017.1290222

44. Bhullar N, Hine DW, Phillips WJ. Profiles of psychological wellbeing in a sample of Australian university students. Int J Psychol. 2014;49(4):288-294. doi:10.1002/ijop.12022

45. Brandel M, Melchiorri E, Ruini C. The dynamics of eudaimonic well-being in the transition to parenthood: differences between fathers and mothers. $J$ Fam Issues. 2018. doi:10.1177/ $0192513 X 18758344$

46. Browne J, Penn DL, Meyer-Kalos PS, et al. Psychological well-being and mental health recovery in the NIMH RAISE early treatment program. Schizophr Res. 2017;185:167-172. doi:10.1016/j.schres.2016.11.032

47. Chaves C, Lopez-Gomez I, Hervas G, Vazquez C. A comparative study on the efficacy of a positive psychology intervention and a cognitive behavioral therapy for clinical depression. Cognit Ther Res. 2016;(April):1-17. doi:10.1007/s10608-016-9778-9

48. Dezutter J, Waterman AS, Schwartz SJ, et al. Meaning in life in emerging adulthood: a person-oriented approach. J Pers. 2014;82 (1):57-68. doi:10.1111/jopy.12033

49. Harris M, Wilson JC, Hughes S, Knevel RJM, Radford DR. Perceived stress and well-being in UK and Australian dental hygiene and dental therapy students. Eur J Dent Educ. 2018;22(3):e602-e611. doi:10.1111/eje. 12360

50. Osafo Hounkpatin H, Wood AM, Boyce CJ, Dunn G. An existentialhumanistic view of personality change: co-occurring changes with psychological well-being in a 10 year cohort study. Soc Indic Res. 2015;121(2):455-470. doi:10.1007/s11205-014-0648-0

51. Schotanus-Dijkstra M, Drossaert CHCC, Pieterse ME, Boon B, Walburg JA, Bohlmeijer ET. An early intervention to promote wellbeing and flourishing and reduce anxiety and depression: a randomized controlled trial. Internet Interv. 2017;9(April2016):15-24. doi:10.1016/j.invent.2017.04.002

52. Ravert RD, Kim SY, Schwartz SJ, et al. The association between sensation seeking and well-being among college-attending emerging adults the association between sensation seeking and well-being among college-attending emerging adults. J. Coll Stud Dev. 2013;54(1):17-28. 
53. Tecuta L, Tomba E. Subjective incompetence as a predictor of treatment outcomes in eating disorder outpatients. Psychiatry Res. 2018;266:193-198. doi:10.1016/j.psychres.2018.05.052

54. Ziadni MS, Jasinski MJ, Labouvie-Vief G, Lumley MA. Alexithymia, defenses, and ego strength: cross-sectional and longitudinal relationships with psychological well-being and depression. $J$ Happiness Stud. 2017;18(6):1799-1813. doi:10.1007/s10902-0169800-7

55. Keyes CLM. The mental health continuum: from languishing to flourishing in life. J Health Soc Behav. 2002;43(2):207-222. doi: $10.2307 / 3090197$

56. Bohlmeijer ET, Lamers SMA, Fledderus M. Flourishing in people with depressive symptomatology increases withacceptance and commitment therapy. post-hoc analyses of a randomized controlled trial. Behav Res Ther. 2015;65:101-106. doi:10.1016/j. brat.2014.12.014

57. Grouden ME, Jose PE. How do sources of meaning in life vary according to demographic factors? NZ J Psychol. 2014;43(3):29-38. Available from: http://ezproxy.unibo.it/login?url=http://search.ebsco host.com/login.asp $x$ ?direct $=$ true $\& d b=$ psyh $\& A N=2015-06095$ 004\&lang=it\&site $=$ ehost-live \&scope $=$ site.

58. Pots WTM, Meulenbeek PAM, Veehof MM, Klungers J, Bohlmeijer ET. The efficacy of mindfulness-based cognitive therapy as a public mental health intervention for adults with mild to moderate depressive symptomatology: a randomized controlled trial. PLoS One. 2014;9:10. doi:10.1371/journal.pone.0109789

59. Singh K, Bassi M, Junnarkar M, Negri L. Mental health and psychosocial functioning in adolescence: an investigation among Indian students from Delhi. $J$ Adolesc. 2015;39:59-69. doi:10.1016/j. adolescence.2014.12.008

60. Trompetter HR, de Kleine E, Bohlmeijer ET. Why does positive mental health buffer against psychopathology? An exploratory study on self-compassion as a resilience mechanism and adaptive emotion regulation strategy. Cognit Ther Res. 2017;41(3):459-468. doi:10.1007/s10608-016-9774-0

61. Walker JV, Lampropoulos GK. A comparison of self-help (homework) activities for mood enhancement: results from a brief randomized controlled trial. J Psychother Integr. 2014;24(1):46-64. doi: $10.1037 / \mathrm{a} 0036145$

62. Diener E, Wirtz D, Tov W, et al. New well-being measures: short scales to assess flourishing and positive and negative feelings. Soc Indic Res. 2010;97:143-156. doi:10.1007/s11205-009-9493-y

63. de Manincor M, Bensoussan A, Smith CA, et al. Individualized yoga for reducing depression and anxiety, and improving well-being: a randomized controlled trial. Depress Anxiety. 2016;33(9):816-828. doi:10.1002/da.22502

64. Chan M, Tsai KM, Fuligni AJ. Changes in religiosity across the transition to young adulthood. J Youth Adolesc. 2015;44(8):15551566. doi:10.1007/s10964-014-0157-0

65. Hervás G, Vázquez C. Construction and validation of a measure of integrative well-being in seven languages: the pemberton happiness index. Health Qual Life Outcomes. 2013;11:66. doi:10.1186/14777525-11-66

66. Muñiz-Velázquez JA, Gomez-Baya D, Lopez-Casquete M. Implicit and explicit assessment of materialism: associations with happiness and depression. Pers Individ Dif. 2017;116:123-132. doi:10.1016/j. paid.2017.04.033

67. Delle FA, Brdar I, Freire T, Vella-Brodrick D, Wissing MP. The Eudaimonic and hedonic components of happiness: qualitative and quantitative findings. Soc Indic Res. 2011;100(2):185-207. doi:10.1007/s11205-010-9632-5

68. Fianco A, Sartori RDG, Negri L, Lorini S, Valle G, Fave AD. The relationship between burden and well-being among caregivers of Italian people diagnosed with severe neuromotor and cognitive disorders. Res Dev Disabil. 2015;39:43-54. doi:10.1016/j. ridd.2015.01.006
69. Kryza-Lacombe M, Tanzini E, O’Neill S. Hedonic and eudaimonic motives: associations with academic achievement and negative emotional states among urban college students. J Happiness Stud. 2018;(0123456789):1-19. doi:10.1007/s10902-018-9994-y

70. Merrick A, Grieve A, Cogan N. Psychological impacts of challenging behaviour and motivational orientation in staff supporting individuals with autistic spectrum conditions. Autism. 2017;21(7):872-880. doi:10.1177/1362361316654857

71. Quitasol MN, Fournier MA, Domenico SIDI, Michael Bagby R, Quilty LC, Changes in psychological need fulfillment over the course of treatment for major depressive disorder. J Soc Clin Psychol. 2018;37(5):381-404. doi:10.1521/jscp.2018.37.5.381

72. Routledge KM, Burton KLO, Williams LM, et al. Shared versus distinct genetic contributions of mental wellbeing with depression and anxiety symptoms in healthy twins. Psychiatry Res. 2016;244:65-70. doi:10.1016/j.psychres.2016.07.016

73. Brooks AM, Ottley KM, Arbuthnott KD, Sevigny P. Nature-related mood effects: season and type of nature contact. J Environ Psychol. 2017;54:91-102. doi:10.1016/j.jenvp.2017.10.004

74. Avsec A, Kavčič T, Jarden A. Synergistic Paths to Happiness: findings from Seven Countries. J Happiness Stud. 2016;17(4):13711390. doi:10.1007/s10902-015-9648-2

75. Brown L, Bryant C, Brown V, Bei B, Judd F. Investigating how menopausal factors and self-compassion shape well-being: an exploratory path analysis. Maturitas. 2015;81(2):293-299. doi:10.1016/j.maturitas.2015.03.001

76. Baselmans BML, Willems YE, van Beijsterveldt CEM, et al. Unraveling the genetic and environmental relationship between well-being and depressive symptoms throughout the lifespan. Front Psychiatry. 2018;9(JUN). doi:10.3389/fpsyt.2018.00261

77. Hallam WT, Olsson CA, O’Connor M, et al. Association between adolescent eudaimonic behaviours and emotional competence in young adulthood. J Happiness Stud. 2014;15(5):1165-1177. doi:10.1007/s10902-013-9469-0

78. Sheldon KM, Hilpert JC. The balanced measure of psychological needs (BMPN) scale: an alternative domain general measure of need satisfaction. Motiv Emot. 2012;36(4):439-451. doi:10.1007/ s11031-012-9279-4

79. Deci EL, Ryan RM. The " what " and " why " of goal pursuits: human needs and the self-determination of behavior. Psychol Inq. 2000;11(4):227-268. doi:10.1207/S15327965PLI1104_01

80. Gatt JM, Burton KLO, Schofield PR, Bryant RA, Williams LM. The heritability of mental health and wellbeing defined using COMPASW, a new composite measure of wellbeing. Psychiatry Res. 2014. doi:10.1016/j.psychres.2014.04.033

81. Tennant R, Hiller L, Fishwick R, et al. The Warwick-Edinburgh Mental Well-being Scale (WEMWBS): development and UK validation. Health Qual Life Outcomes. 2007;5:63. doi:10.1186/1477-7525$5-63$

82. Cantril H. The pattern of human concerns. New Brunswick. 1967.

83. Stone W. Measuring social capital: towards a theoretically informed measurement framework for researching social capital in family and community life. Aust Inst Fam Stud. Volume 24. Melbourne, Australia. 2001. ISSN 1440-4761.

84. Lovibond SH, Lovibond PF. Manual for the Depression Anxiety Stress Scales. Sydney, Australia: Psychology Foundation Monograph; 1995. doi:10.1016/0005-7967(94)00075-U

85. Teismann T, Brailovskaia J, Totzeck C, Wannemüller A, Margraf J. Predictors of remission from panic disorder, agoraphobia and specific phobia in outpatients receiving exposure therapy: the importance of positive mental health. Behav Res Ther. 2018;108(February):40-44. doi:10.1016/j.brat.2018.06.006

86. Radloff LS. The CES-D Scale: a self-report depression scale for research in the general population. Appl Psychol Meas. 1977. doi:10.1177/014662167700100306 
87. Zigmond AS, Snaith RP. The hospital anxiety and depression scale. Acta Psychiatr Scand. 1983. doi:10.1111/j.1600-0447.1983.tb09716.x

88. Beck AT, Steer RA, Brown GK. Manual for the Beck Depression Inventory-II. San Antonio: TX Psychol Corp; 1996.

89. Cox JL, Holden JM, Sagovsky R. Detection of postnatal depression: development of the 10-item Edinburgh postnatal depression scale. $\mathrm{Br}$ J Psychiatry. 1987. doi:10.1192/bjp.150.6.782

90. Seow LSE, Vaingankar JA, Abdin E, et al. Positive mental health in outpatients with affective disorders: associations with life satisfaction and general functioning. $J$ Affect Disord. 2016;190:499-507. doi:10.1016/j.jad.2015.10.021

91. Achenbach TM, Rescorla LA. Manual for the ASEBA Adult Forms \& Profiles. Burlington, VT: University of Vermont; 2003.

92. Addington D, Addington J, Maticka-Tyndale E. Assessing depression in schizophrenia: the calgary depression scale. Br J Psychiatry. 1993. doi:10.1192/S0007125000292581

93. Kanter JW, Mulick PS, Busch AM, Berlin KS, Martell CR. The Behavioral Activation for Depression Scale (BADS): psychometric properties and factor structure. J Psychopathol Behav Assess. 2007. doi:10.1007/s10862-006-9038-5
94. Olsen LR, Jensen DV, Noerholm V, Martiny K, Bech P. The internal and external validity of the major depression inventory in measuring severity of depressive states. Psychol Med. 2003. doi:10.1017/ S0033291702006724

95. Kroenke K, Spitzer RL. The PHQ-9 : a new depression measure. Psyciatric Ann. 2002. doi:10.3928/0048-5713-20020901-06

96. Lopez-Gomez I, Chaves C, Hervas G, Vazquez C. Comparing the acceptability of a positive psychology intervention versus a cognitive behavioural therapy for clinical depression. Clin Psychol Psychother. 2017;(April):1029-1039. doi:10.1002/cpp.2129

97. Westerhof GJ, Keyes CLM. Mental illness and mental health: the two continua model across the lifespan. J Adult Dev. 2010;17(2):110-119. doi:10.1007/s10804-009-9082-y

98. Fava GA, Ruini C. What is the optimal treatment of mood and anxiety disorders? Clin Psychol Sci Pract. 2005;12(1):92-96. doi:10.1093/clipsy.bpi011

99. Rashid T. Positive interventions in clinical practice. J Clin Psychol. 2009;65(5):461-466. doi:10.1002/jclp.20588
Psychology Research and Behavior Management

\section{Publish your work in this journal}

Psychology Research and Behavior Management is an international, peer-reviewed, open access journal focusing on the science of psychology and its application in behavior management to develop improved outcomes in the clinical, educational, sports and business arenas. Specific topics covered in the journal include: Neuroscience, memory and decision making; Behavior modification and management; Clinical

\section{Dovepress}

applications; Business and sports performance management; Social and developmental studies; Animal studies. The manuscript management system is completely online and includes a very quick and fair peer-review system, which is all easy to use. Visit http://www. dovepress.com/testimonials.php to read real quotes from published authors. 